\title{
Response of adult dragonflies to prey of different size and colour in the context of anti-predator defences.
}

\author{
by \\ Minh Tam Duong \\ A thesis submitted to \\ the Faculty of Graduate and Postdoctoral Affairs \\ in partial fulfillment of the requirements for the degree of
}

Master of Science

in

Biology

Carleton University
Ottawa, Ontario

(C) 2016

Minh Tam Duong 


\begin{abstract}
Warning coloration is used by many prey species to advertise their unpalatability to potential predators and the evolution of such signals is strongly influenced by predator behaviour. I begin by reviewing the past literature on the potential role of invertebrates in shaping the evolution of warning signals in aposematism and mimicry. I then describe an investigation of the behaviour adult dragonflies in response to artificial prey of varying shape and colour, to determine the role of these traits in influencing foraging decisions. In two experiments, dragonfly species and sex, and prey size, influenced prey selection. However, neither prey colour, nor its interaction with prey size, affected the rate of attack of dragonflies. Through a feeding experiment, I also found that dragonflies preferred to feed on insects with softer exoskeletons. The implications of these findings for the evolution of warning signals and mimicry in small aerial insects are discussed.
\end{abstract}




\section{ACKNOWLEDGMENTS}

I would first like to express my most sincere gratitude and thanks to my supervisor, Dr. Tom Sherratt, for his support, understanding, patience, and guidance throughout my Master's journey. I am honoured to have been given the opportunity to continue my education and grow as a scientist and person. I am extremely grateful for the people I have met, both academic and personal, the international conference in Exeter, England I was able to participate in, and the field research I conducted at the Queens University Biological Station - all of which were made possible by Dr. Tom Sherratt.

Many thanks go to my thesis advisory committee for their advice and feedback during committee meetings as well as their patience as I finished my thesis. I would like to dedicate a special thank you to Dr. Changku Kang who helped me polish my R-skills, offered me valuable advice and guidance, and provided encouragement throughout my thesis. This appreciation is extended to my lab mates with whom I have made countless memories during my time in Ottawa. A special thank you goes to Ann Gomez for being a stellar field assistant and partner in crime during the field seasons and to Sophie Potter who went from co-worker, to roommate, to lifelong friend, with her limitless support throughout our friendship.

I would also like to thank the staff at QUBS who made our stay comfortable by helping me with inquiries, providing hearty meals, and creating a community conducive to productivity and successful research. I am grateful for the QUBS community, full of passion, that has allowed me to meet so many interesting people and to make lasting memories that I will cherish forever.

Finally, I would like to thank my mom and dad, Ha Nguyen and Bon Duong, for their unwavering and never-ending support throughout my academic endeavours. In addition, to family and friends for their support despite their concern that I would be leaving home to "do something with bugs". Lastly, to my partner, Eden Liu, who has been with me through all the ups and downs that came before, during, and after this experience and for his unconditional support and guidance. 


\section{TABLE OF CONTENTS}

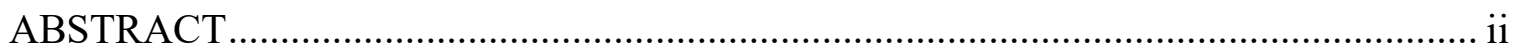

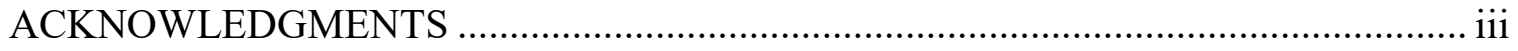

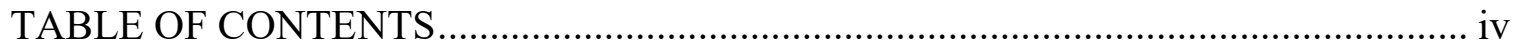

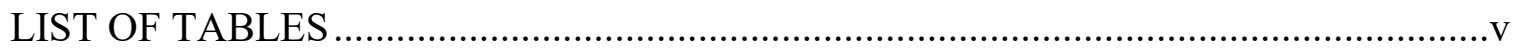

LIST OF FIGURES .................................................................................... vi

LIST OF APPENDICES .......................................................................................... vii

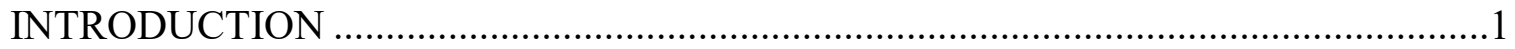

CHAPTER 1: A REVIEW OF INVERTEBRATE PREDATION ON APOSEMATIC

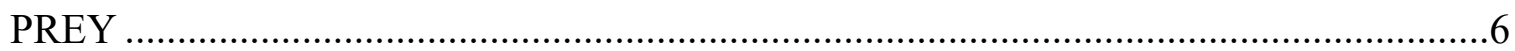

CHAPTER 2: PREY SIZE ALONG WITH PREDATOR SPECIES AND SEX

INFLUENCES FORAGING DECISIONS IN A COMMUNITY OF ADULT

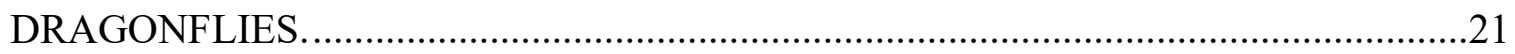

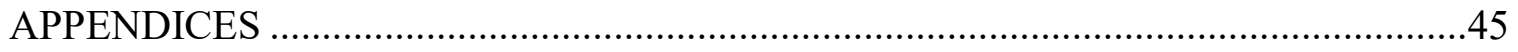

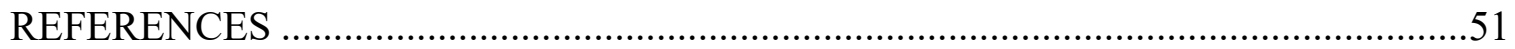




\section{LIST OF TABLES}

Table 1. Experimental studies that have investigated aposematism using invertebrate predators and their main findings. Studies are categorized by the invertebrate predator

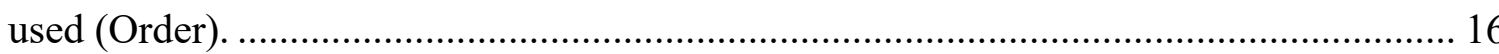

Table 2. Summary of species included in the community choice experiment analyses, relative total body length (head to abdomen tip), given size-class category, and the number of individuals tested...

Table 3. ANOVA results of a binomial logistic regression testing for the effects of prey size, prey colour, dragonfly size class, and their interactions on the proportion of treatment prey attacked in the community choice experiment. Shown are the final model equation, the model's parameters, chi-squared values, degrees of freedom, $p$-values for each variable.

Table 4. Number of prey presentations and attacks made by females and males of Leucorrhinia intacta and Libellula pulchella. 39 


\section{LIST OF FIGURES}

Figure 1. Empirical work investigating aposematism (total: 272; 1900 - 2016) and the proportion of studies separated by predator groups (fish, birds, invertebrates, reptiles and amphibians, mammals, and other (models, theoretical work, reviews))

Figure 2. Artificial prey made from two conjoined beads, painted with acrylic paint in two colours (black and black/yellow striped) in various size treatments (2.5 (black only), $5,9,12,16,18$, and $31 \mathrm{~mm})$. The standard bead used in each pairwise presentation is denoted $(*)$

Figure 3. The proportion of attacks on treatment beads (compared to standard bead) by a community of adult dragonflies on prey of varying size (2.5 (black only), 5, 9, 12, 16, 18, and $31 \mathrm{~mm}$ ) in two colours (black and black/yellow striped). Error bars show the binomial 95\% confidence intervals

Figure 4. The probability of attack on treatment bead (compared to standard bead) by smaller dragonflies (C. elisa, C. eponina, L. intacta, L. glacialis, Sympetrum spp., E. cynosura, L. frigida, P. longipennis) versus larger dragonflies (L. quadrimaculata, G. spicatus, L. pulchella, L. julia, and L. luctuosa) on prey of varying size (2.5 (black only), $5,9,12,16,18$, and $31 \mathrm{~mm}$ ) for both colour treatments.

Figure 5. Cumulative survivorship curves (probability of survival) for prey (5 and 12 $\mathrm{mm}$; lengthwise) against female (top) and male (bottom) dragonflies of two species (Leucorrhinia intacta and Libellula pulchella). Censored observations are denoted by “+”. Large prey were not attacked by males of either species thus survival lines are overlapping at 1.0 


\section{LIST OF APPENDICES}

\section{Appendix A}

Table A1. Frequency of different prey types (Diptera, Hymenoptera, Hemiptera, Lepidoptera) fed on by dragonflies and the frequency of female and males dragonflies

that accepted prey. A total of 92 feeding events occurred............................................. 48

\section{Appendix B}

Figure A1. Spectral curves for the black and yellow paint used to create the artificial prey.

Figure A2. The probability of attack on treatment bead (compared to standard bead) by smaller dragonflies (0; C. elisa, C. eponina, L. intacta, L. glacialis, Sympetrum spp., E. cynosura, L. frigida, P. longipennis) versus larger dragonflies (1; L. quadrimaculata, G. spicatus, L. pulchella, L. julia, and L. luctuosa) on prey of varying size (2.5 (black only), $5,9,12,16,18$, and $31 \mathrm{~mm}$ ) for both colour treatments and the frequency of attacks. ... 50 


\section{INTRODUCTION}

This thesis focuses on elucidating how invertebrate predators can shape antipredator defences in invertebrate prey, mainly explored using adult foraging dragonflies. The Introduction is divided into three sections. The first section is a general overview of the evolution of conspicuous ("warning") signals in defended prey, i.e. aposematism (Poulton 1890). The second section reviews invertebrate predation and the foraging behaviour of dragonflies, in general and in the context of aposematism. The last section of this introduction is a summary of thesis goals and objectives.

\section{Aposematism}

Many prey species have evolved adaptations to avoid being consumed by potential predators, which can be behavioural, morphological, and/or physiological (Ruxton et al., 2004). These anti-predator adaptations work to reduce detection or recognition, capture, and/or consumption and are highly diverse across different taxa (Edmunds, 1974). Examples of different defences include camouflage (Cott, 1940), masquerade (Skelhorn et al., 2010), spines or shells (Edmunds, 1974), chemical defences (Ruxton et al., 2004), and mimicry (Bates, 1862); species can use one or more of these defences to deter predators and at different stages of the predation sequence.

One might expect it to be mutually beneficial for defended prey to signal their unprofitability to would-be predators, and for predators to pay attention to these signals. Aposematism is an evolved cross-species association between a species' unprofitability to attack and the presence of conspicuous signals (Poulton 1890; Ruxton et al. 2004). One hypothesis as to why organisms with chemical defences tend to be conspicuous is that by distinguishing themselves from those that lack chemical defences, they advertise through 
their appearance or behaviour that there is a cost in attacking them (Wallace, 1889). More proximately, it is hypothesized that conspicuousness can aid in prey recognition and increase memorability of prey, thus allowing faster avoidance learning by predators (Ruxton et al., 2004). Distinct colours and patterns can act as salient features to decrease the time needed for learning (Bowdish and Bultman, 1993; Marples et al., 1994; Kazemi et al., 2014) but standing out from the background can also allow faster learned avoidance (Gittleman and Harvey, 1980). The mechanisms and processes that underlie aposematism are still being investigated (Skelhorn et al., 2016) but so far work has focused predominantly on the effect of conspicuous signals on avian predators.

\section{Invertebrate predation and study organism}

Despite the fact that many invertebrates are insectivores and voracious predators, birds have long been considered the primary selective pressure on insects. Literature has continually reflected the importance of birds as insectivorous predators (Poulton, 1890; Guilford, 1990) and has long overlooked the potential role of invertebrates as predators. This oversight is surprising considering their high abundance and the various taxa of carnivorous invertebrates such as praying mantids, dragonflies, robber flies, beetles, hunting spiders, hornets, and ants, to name a few. Invertebrates range from sit-and-wait predators to active hunters, with many being predacious throughout their life cycle. Terrestrial prey are likely exposed to a wide array of predators, all of which exhibit different visual capabilities, prey preferences, and foraging behaviour. To date, there has been no justification for the emphasis on avian predators or the lack of work on invertebrate predators. Throughout my thesis, I discussed the importance of invertebrate predators in the hope that future studies will further consider this neglected area. 
I used adult dragonflies as my model species to investigate the foraging behaviour of predatory invertebrates on aposematic prey for various reasons. First, they are voracious predators that are carnivorous in their larval and adult stage. Adults eat at least $60 \%$ of their body weight daily and can eat more than $100 \%$ of their body weight daily during the prereproductive season (Corbet, 1999). Second, they feed primarily on Hymenoptera and Diptera, a model system for studies of aposematism and mimicry due to the richness of species in these groups exhibiting warning coloration. Third, with their head consisting mainly of their eyes, dragonflies are highly visual predators that can detect motion, colour (both visible and ultraviolet) (Yang and Osorio, 1996), and polarized light for various reasons (e.g. prey capture, species recognition, mating, egg laying, etc.) (Corbet, 1999). The ommatidia of the dragonfly eye are divided into specialized regions that vary in morphology and physiology depending on the process they are responsible for (Corbet, 1999). It is known that motion plays a significant role in prey capture for dragonflies but is it presently unclear whether visual cues such as colour are used (Olberg et al., 2000).

Many studies have studied the role of dragonflies in predator-prey interactions but far fewer have investigated their potential role on selection for anti-predator defences including aposematism and mimicry. To date, two studies have investigated the foraging behaviour of dragonflies in response to aposematic prey. Kauppinen and Mappes (2003), offered wasp-like artificial prey to brown hawker dragonflies (Aeshna grandis) and measured their behavioural responses, ranging from "observed but did not touch" to "touched and consumed". They found that dragonflies avoided wasp-like prey (i.e. blackyellow stripes). However, their measure of responsive behaviour does not imply a selective pressure (few prey of any type were actually attacked) and can simply be a result of 
increased attention to conspicuous objects. Rashed et al. (2005) offered a variety of prey (e.g. Hymenopteran models, Dipteran mimics, painted natural and artificial prey) to a community of dragonflies and found no evidence to support the hypothesis that colour provided protective benefits to prey. However, they did find a significant preference for smaller prey. Although these studies were methodologically similar, the contrasts in their results makes it difficult to conclude whether dragonflies have played a role in shaping aposematic signals in Dipteran and/or Hymenopteran prey.

\section{Thesis objectives and predictions}

The general goal of my thesis was to investigate the potential selective role of invertebrate predators on warning coloration, more specifically, the foraging behaviour of adult dragonflies and their response to variation in prey coloration and size. One of the main questions was whether prey colour and size would interact to provide protective benefits and increase prey survival. My thesis is comprised of three field experiments: a community choice experiment, a species-specific choice experiment, and a feeding experiment.

First, I conducted a pairwise-choice experiment to determine the foraging decisions of dragonflies with regard to different prey features. I used artificial prey in two colours (black-yellow striped and solid black) and in six different sizes (paired beads ranging from $2.5-30 \mathrm{~mm}$, lengthwise). Based on previous studies (Kauppinen and Mappes, 2003; Rashed et al., 2005), I predicted that (i) dragonflies would overall prefer smaller prey, but that (ii) warning coloration would shift optimal prey preference peaks towards larger sized prey due to the protective benefits from an interaction between prey colour and size and that (iii) different dragonfly species would vary in their prey size and colour preferences. 
Second, I conducted a single-choice experiment exploring the tendency of two, common dragonfly species that differed in size to attack prey with given characteristics. I was particularly interested in establishing whether dragonfly species and sex affected foraging decisions. To do this I offered two prey sizes (black; 5 and $12 \mathrm{~mm}$ ) to both sexes of small and large species of dragonfly, Leucorrhinia intacta and Libellula pulchella. I predicted that $L$. intacta would be limited by their size when attacking prey and thus would target mainly smaller prey, while L. pulchella would attack prey of both sizes.

The last experiment I conducted was a simple feeding experiment to determine whether dragonflies would eat all types of prey given the opportunity. To do this, I handfed adult dragonflies a variety of prey species that were present in the same area. Based on an observation made during the previous experiment, I predicted that dragonflies would feed on most prey items offered except for ones with heavily sclerotized exoskeletons (e.g. lady bird beetles) and would spend no or less time feeding on physically defended prey (Appendix A). 


\section{CHAPTER 1: A REVIEW OF INVERTEBRATE PREDATION ON APOSEMATIC PREY}

\section{Introduction}

Conspicuous signals in defended prey species appear to advertise to potential predators that they are unpalatable; this association between unprofitability and conspicuous signals is an anti-predator defence known as aposematism (Poulton, 1890; Edmunds, 1974; Ruxton et al., 2004). Historically, this field has rightly focused on the evolution of these signals in prey species from the prey perspective but clearly there are two sides to predator-prey interactions: predator behaviour and cognition are also essential factors that drive predator-prey interactions. For instance, in many evolutionary models of aposematism, changes in predator behaviour parameters can strongly influence how prey warning signals evolve (Sherratt, 2002; Endler and Mappes, 2004). Moreover, for aposematism to function, predators must be able to discriminate between aposematic and non-aposematic prey, learn to associate the warning signal(s) and unprofitability through experience, remember the experience, and recognize aposematic prey upon further encounters (Ruxton et al., 2004). Many studies have aimed to demonstrate one or some of these behaviours in a variety of predators.

Empirical (and theoretical) work on aposematism has long considered birds as the primary selective pressure on aposematic prey (i.e. insects) (Fig. 1). In theoretical evolutionary models, parameters are often based on bird behaviour and/or vision and drawn from empirical studies using bird predators (Gittleman \& Harvey, 1980; Marples et al., 1994; Roper and Marples, 1997; Marples et al., 1998; Mappes et al. 1999; Gamberale-Stille and Tullberg 2001; Exernova et al. 2003; Kazemi et al., 2014). The evolution of warning 
signals is often considered paradoxical because the first conspicuous individual would be subject to higher likelihood of detection and predation (given that they are not recognized as unprofitable) but researchers have argued that survival is possible if predators demonstrate conservative foraging/dietary conservatism (Sherratt 2002; Thomas et al., 2003; Marples et al., 2005) and/or if defended prey are capable of surviving attacks (Wiklund and Jarvi, 1982). However, dietary conservatism has not been widely investigated in other predatory groups besides birds (but see Thomas et al. (2010) where this behaviour was observed in fish). Other phenomena such as innate aversion, visual cues used in learning, salient features, and signal efficacy are important components in the functioning of warning signals, yet, studies of these have been heavily avian focused (but see Nelson et al. (2006) for innate aversion in mantids). There is no doubt that many birds are insectivores and can impose major types of selection but investigation of other, ecologically relevant predators, would create a more comprehensive understanding of the various selection pressures prey are subject to.

Although some empirical work has investigated how different predators use warning signals (fish: Ang \& Newman 1998, Thomas et al., 2010, Chiao et al, 2011; reptiles and amphibians: Hatle \& Salazar, 2001, Bonacci et al., 2008; mammals: Bonacci et al., 2004, Brandmayr et al., 2008) the literature is primarily focused and supported by work with birds. The lack of work on terrestrial invertebrates in this area is surprising considering their prevalence, observed aversion to aposematic prey (Bates, 1862; O'Donnell, 1995), and knowledge that many of them are visually driven foragers. Here, I reviewed the work that has been done with invertebrate predators in the context of 
aposematism and how their behaviour could affect or shape the evolution of (warning) coloration in prey species.

I was interested in studies that focused on predator-prey interactions within the context of aposematism, and in particular in elucidating the proportion of these studies were conducted with, or inspired by, invertebrate predators. I therefore conducted an online search using the Web of Science database with "aposematism" and "aposematic" as keywords, from 1900-2016. Of 604 studies found related to these keywords, 272 studies focused on predator-prey interactions and were further divided into focal predator groups (aquatic systems, birds, invertebrates, reptiles and amphibians, humans, mammals, and other (models, theoretical work, reviews)) (Fig. 1). Studies using invertebrate predators were further categorized by the taxonomic order. The remaining 332 studies were not included because they did not pertain to predator-prey interactions, which was my main interest, but rather looked at a variety of related topics (e.g. species-specific chemical defences, phylogenies, reviews of the parameters of aposematism, etc.). 


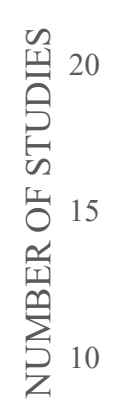

)

198719891990199319941995199619971998199920002001200220032004200520062007200820092010201120122013201420152016 YEAR PUBLISHED
- Fish $\quad$ Birds $\quad$ Invertebrates
- Reptiles \& amphibians
- Mammals
- Other

Figure 1. Empirical work investigating aposematism (total: 272; 1900 - 2016) and the proportion of studies separated by predator groups (fish, birds, invertebrates, reptiles and amphibians, mammals, and other (models, theoretical work, reviews)). 


\section{Invertebrate predators in experimental work}

One of the most telling outcomes of my quantitative analysis of studies investigating aposematism was that I found only $21(8 \%)$ empirical experiments testing the response of invertebrate predators to the aposematic prey (Table 1). In comparison, 153 papers $(56 \%)$ used birds. Rather than disinterest, the disinclination to use invertebrate predators in studies of aposematism could at least in part be due to limitations in rearing, housing, or maintaining them in laboratories. Aerial invertebrates such as dragonflies and robber flies, are particularly difficult to keep in a lab because they require large spaces, specific conditions, and free-ranging prey (but see Mischiati et al., 2015). Koch (2014) found that hand-feeding dragonflies in outdoor enclosures increased their survival but this can be a time-consuming task. In contrast, non-aerial invertebrates (e.g. mantids, various arachnids, beetles, etc.) are easier to maintain in laboratories, which is reflected in the literature as they are commonly used as study species (Table 1).

Among the invertebrate studies, mantids (Mantodea) are the most commonly used insect, which (as noted above) is likely due to ease of acquisition, their persistence in captivity, and simple care protocols. Many mantids are generalist and opportunistic feeders but are often found near flowering plants that attract high densities of prey (Reitze and Nentwig, 1991). Early work by Gelperin (1968) showed that mantids (Paratenodera sinensis and Mantis religiosa) were capable of learned aversion to distasteful milkweed bugs (Oncopeltus fasciatus) and that their feeding behaviour could be modified by negative reinforcement. Berenbaum and Miliczky (1984) expanded these findings by showing that mantids (Tenodera sinensis) that experienced unpalatable milkweed bugs (O. fasciatus) avoided subsequent palatable conspecifics, providing evidence for automimicry as an 
effective anti-predator defence against mantids. Features such as stripes (Bowdish and Bultman, 1993) and high prey luminance contrast (Prudic et al., 2007) have also been shown to facilitate aversion learning in mantids ( $T$. sinensis) by decreasing learning time. Recent work with mantids highlighted an important issue when investigating antipredator defences that rely on visual cues, which is the pairing between the prey's signal and the visual system of the intended predator. Fabricant and Herberstein (2015) found that Harlequin bugs (Tectocoris diophthalmus) painted bright orange, placed on a leaf, were cryptic to mantids from afar but could induce avoidance learning in birds. In the same system, Fabricant and Smith (2014) found that the same bugs (naturally colourful and iridescent) were conspicuous (hence aposematic) to domestic chicks but not mantids, which emphasizes the importance of testing multiple, ecologically relevant predators. Mantids (T. sinensis) have also shown taste-rejection behaviour when dealing with aposematic prey such as gutting monarch caterpillars (Danaus plexippus) before consumption, presumably to decrease toxin ingestion (Rafter et al., 2013). These studies suggest that mantids are capable of generating selection as they can learn to avoid aposematic prey but the visual cues they use to learn are more likely to be patterns and luminance contrast (e.g. iridescence), rather than specific colours.

Another commonly studied predatory group due to their ease of rearing in laboratories are spiders. Jumping spiders are particularly favoured due to their known visual capabilities (Harland et al., 2012) and voracity (Jackson and Pollard, 1996). An early study investigating spiders (Zygiella x-notata) and birds (Parus major) found that both predators could learn to discriminate between aposematic aphids (Aphis nerii) and cryptic, palatable aphids (Acyrthosiphon pisum) (Malcolm, 1985). McIver and Lattin (1990) tested 
four species of spiders (jumping: Sassacus papenhoei and Phidippus cardinalis; crab: Xysticus rnontanensis; flower: Misumenops celer) and an assassin bug (Sinea diadena) and found that jumping and crab spiders rejected Lopidea nigridea, an aposematic plant bug. Skow and Jacob (2006) trained jumping spiders (Phidippus princeps) to avoid distasteful milkweed bugs (O. fasciatus); they further showed that if spiders were taken out of the environment where they were taught, spiders would not retain the trained aversion in the new environment. Context-dependent learning and foraging plasticity are important factors to consider in predatory behaviour, especially since the fundamentals of aposematism rely on retaining the unprofitable association from previous experiences. In addition, Long et al. (2012) showed that jumping spiders (P. princeps and Phidippus audax) could use noncolour related signals such as simulated firefly defences (Photuris sp.) (i.e. flashing LED lights) as learning cues for prey unpalatability. In more recent work with jumping spiders (Habronattus pyrrithrix), Taylor et al. (2014) found that field-caught as well as naïve spiders had colour biases towards blue prey and against red, yellow, and green prey. Notably, field-caught spiders lost their colour biases after being housed in laboratories for several weeks. Taylor et al. (2016) found similar results after teaching jumping spiders ( $H$. pyrrithrix) to either accept or reject red-coloured prey and found that preferences were lost within two weeks if not reinforced. These two studies show that this species of jumping spider can generate selection on aposematic prey and that learning is adaptive and responsive to the prey population. In recent work with crab spiders, their unspecific selectivity for different Diptera and Hymenoptera (i.e. a variety of mimics and models, respectively) suggests that they could be a source of relaxed selection on mimetic fidelity within these groups; they also found that spiders with prior aversion to wasps, avoided 
subsequent black-yellow striped prey (natural and artificial) (Morris and Reader, 2016). All together, these studies suggest that visually driven hunting spiders are capable of generating various forms of selection on prey coloration as well as modifying their foraging behaviour based on experience and available prey population.

Outside of mantids and arachnids, very little work has been done on other groups of invertebrates. Reader and Hochuli (2003) investigated the foraging preferences of the common assassin bug (Reduviidae: Pristhesancus plagipennis), which are generalist predators but have been known to commonly feed on honey bees, various true bugs, and crop pest species (Grundy et al., 2000). They found that assassin bugs were less likely to attack aposematic caterpillars (Doratifera casta) when they were in large than small aggregations. Murphy et al. (2010) presented assassin bugs (Pselliopus sp.), paper wasps (Polistes fuscatus and Polistes dominulus) and lacewing larvae with spined and unspined limacodid moth larvae (spines are connected to a poison sac). They found that all three generalist predators preferred unspined larvae and that wasps were aversive upon further encounters. They also observed an assassin bug feeding on a caterpillar from below, using its beak to pierce the leaf and caterpillar, implying there are adaptive behaviours to avoid damage from spine defences. Bonacci et al. (2006) tested the feeding behaviour of a Staphylinid beetle (Ocypus olens) against three beetles with warning coloration and chemical defences and five without such characteristics. The predatory beetle attacked unprotected prey more frequently than protected prey but whether discrimination was based on visual or olfactory cues was not discerned. Tabadkani and Nowzari (2015) also found that predatory ground beetles (Chlaenius pallipes) preferred non-toxic species of rove beetles over a toxic species (Paederus fuscipes, black and orange beetles that use 
pederin as a chemical defence) and that the pederin compound had highly adverse effects on mobility and mortality in another predatory beetle (Nebria brevicollis).

With respect to dragonflies, Bates (1862) observed dragonflies avoiding Heliconiid butterflies and O'Donnell (1996) observed dragonflies inspecting but not attacking wasps. In both studies, the cause (e.g. innate aversion, learned response) for this aversion is unknown but recent studies imply it isn't due to colours or odours (Kauppinen and Mappes, 2003; Rashed et al., 2005). Kauppinen and Mappes (2003) found that wasp odour did not deter dragonflies (Aeshna grandis) but dragonflies reacted less to wasp-like like artificial prey (i.e. black-yellow striped prey). In contrast, Rashed et al. (2005) found no effects of prey type (mimetic and non-mimetic Diptera and Hymenoptera) or colour (black, red, and black-yellow striped) on attack rates within a community of dragonflies but noted that dragonflies attacked smaller prey significantly more.

Recent work has begun to explore invertebrate behaviour in response to non-visual warning signals. Murray et al. (2016) hypothesized that since red-legged banana spiders (Cupiennius coccineus) and neotropical bullet ants (Paraponera clavata) often predate non-toxic frogs, they would also prey upon juvenile dendrobatid frogs (Oophaga pumilio) due to lower chemical defences. Banana spiders refused all dendrobatid frogs, regardless of life stage, but bullet ants fed on significantly more juvenile than adult dendrobatid frogs, suggesting they are able assess the degree of chemical defences. Jones et al. (2016) investigated "olfactory infectious aposematism" in an intriguing system where entomopathogenic nematodes (Heterorhabditis bacteriophora) prevent predators from feeding on their hosts' carcass using warning visual cues for avian predators and warning olfactory cues for invertebrate predators. They found that olfactory cues given off by aging 
nematode-infected carcasses deterred foraging beetles (Pterostichus madidus) and functioned as "parasite-induced aposematism" to prevent host consumption. In general, non-visual warning signals are another aspect of aposematism that is often overlooked. Yet, many prey species that are considered aposematic are multi-faceted with a variety of anti-predator defences that may or may not contribute to aposematism. Visual cues are often also paired with morphological defences, olfactory cues, and/or behaviours (e.g. spines on caterpillars, the "unken" reflex in frogs) (Bajger, 1980; Murphy et al. 2010; Rowe and Halpin, 2013).

Together, these studies suggest that invertebrates are capable of imposing selection for aposematism. Thus, they can use visual or morphological cues to learn and discriminate between prey types and recall such information upon further encounters. In addition, many are capable of flexible, adaptive behaviour in response to prey defences and quality, which is essential in predator learning (Skelhorn et al., 2016). Despite the plethora of evidence demonstrating that invertebrate predatory behaviour can be influenced by warning signals, they have been consistently understudied in the field of aposematism and mimicry. 
Table 1. Experimental studies that have investigated aposematism using invertebrate predators and their main findings. Studies are categorized by the invertebrate predator used (Order).

\begin{tabular}{|c|c|c|}
\hline $\begin{array}{l}\text { Invertebrate } \\
\text { Predator } \\
\text { (Order) }\end{array}$ & Main Findings & Reference \\
\hline Odonata & $\begin{array}{l}\text { Black and yellow stripes in various treatments resulted in } \\
\text { reduced attack by Brown Hawker dragonflies }(A \text {. grandis }) \text {. }\end{array}$ & $\begin{array}{l}\text { Kauppinen \& } \\
\text { Mappes, } 2003\end{array}$ \\
\hline Odonata & $\begin{array}{l}\text { Community of dragonflies preferred smaller prey and } \\
\text { exhibited no aversion to black and yellow patterned prey } \\
\text { (natural (hoverflies, flies, small wasps) and artificial } \\
\text { (beads)). }\end{array}$ & $\begin{array}{l}\text { Rashed et al., } \\
2005\end{array}$ \\
\hline Araneae & $\begin{array}{l}\text { Spiders }(Z . x \text {-notata }) \text { and birds }(P . \text { major }) \text { learned with } \\
\text { time and experience to avoid aposematic aphids }(A \text {. nerii }) \\
\text { over palatable aphids }(A \text {. pisum }) \text {. }\end{array}$ & $\begin{array}{l}\text { Malcolm, } \\
1985\end{array}$ \\
\hline Araneae & $\begin{array}{l}\text { Jumping spiders ( } P \text {. princeps) were trained to discern } \\
\text { palatable and unpalatable milkweed bugs but the learned- } \\
\text { aversion for the latter disappeared when taken out of } \\
\text { environmental context (i.e. aversion learning was context } \\
\text { dependent). }\end{array}$ & $\begin{array}{l}\text { Skow \& } \\
\text { Jakob, } 2006\end{array}$ \\
\hline Araneae & $\begin{array}{l}\text { Flashing lights, such as those used by fireflies, can } \\
\text { facilitate aversion learning in jumping spiders (Phidippus } \\
\text { princeps and Phidippus audax). }\end{array}$ & $\begin{array}{l}\text { Long et al., } \\
2012\end{array}$ \\
\hline Araneae & $\begin{array}{l}\text { Evidence that field-caught and naïve jumping spiders }(H \text {. } \\
\text { pyrrithrix) preferred blue prey and attacked red, yellow, } \\
\text { and green prey less frequently. }\end{array}$ & $\begin{array}{l}\text { Taylor et al., } \\
2014\end{array}$ \\
\hline Araneae & $\begin{array}{l}\text { Crab spiders (S. globosum) use visual cues when foraging } \\
\text { but exhibited minimal aversion learning towards wasps } \\
\text { and bees (mimics and models). }\end{array}$ & $\begin{array}{l}\text { Morris \& } \\
\text { Reader, } 2016\end{array}$ \\
\hline $\begin{array}{l}\text { Araneae \& } \\
\text { Hemiptera }\end{array}$ & $\begin{array}{l}\text { Three different spiders (jumping: } S \text {. papenhoei and } \\
\text { P.cardinalis; crab: X. rnontanensis) rejected the scarlet } \\
\text { plant bug (L. nigridea) against a palatable plant bug. The } \\
\text { flower spider }(M \text {. celer) and the assassin bug }(S \text {. diadena) } \\
\text { did not avoid the plant bugs. }\end{array}$ & $\begin{array}{l}\text { McIver \& } \\
\text { Lattin, } 1990\end{array}$ \\
\hline $\begin{array}{c}\text { Araneae \& } \\
\text { Hymenoptera }\end{array}$ & $\begin{array}{l}\text { Bullet ants ( } P \text {. clavata) fed on juvenile poison dart frogs } \\
(O \text {. pumilio) more than adults (due to lower chemical } \\
\text { defences) but banana spiders }(C \text {. coccineus }) \text { fed on neither. }\end{array}$ & $\begin{array}{l}\text { Murray et al., } \\
2016\end{array}$ \\
\hline Mantodea & $\begin{array}{l}P . \text { sinensis and } M . \text { religiosa learned to avoid milkweed } \\
\text { bugs }(O \text {. fasicatus }) \text { and trained to avoid blowflies via shock } \\
\text { treatments. }\end{array}$ & Gelperin, 1968 \\
\hline
\end{tabular}




\begin{tabular}{|c|c|c|}
\hline Mantodea & $\begin{array}{l}\text { After learning to avoid unpalatable milkweed bugs }(O \text {. } \\
\text { fasicatus }), T \text {. sinensis also avoided palatable and non-toxic } \\
\text { milkweed bugs. }\end{array}$ & $\begin{array}{l}\text { Berenbaum } \\
\text { and Miliczky, } \\
1984\end{array}$ \\
\hline Mantodea & $\begin{array}{l}\text { T. ardifolia learned to delay attacks on unpalatable } \\
\text { milkweed bugs and had the tendency to attack solid- } \\
\text { coloured bugs over patterned bugs. }\end{array}$ & $\begin{array}{l}\text { Bowdish \& } \\
\text { Bultman, } 1993\end{array}$ \\
\hline Mantodea & $\begin{array}{l}\text { T. sinensis attacked more palatable milkweed bugs that } \\
\text { were high-contrast over low-contrast, and learned faster to } \\
\text { avoid bugs that were high-contrast. }\end{array}$ & $\begin{array}{l}\text { Prudic et al., } \\
2007\end{array}$ \\
\hline Mantodea & $\begin{array}{l}\text { T. sinensis will gut monarch caterpillars ( } D \text {. plexippus) but } \\
\text { wholly eat other non-toxic prey species. }\end{array}$ & $\begin{array}{l}\text { Rafter et al., } \\
2013\end{array}$ \\
\hline Mantodea & $\begin{array}{l}\text { Mantises (H. majuscule) preferred iridescent stinkbugs } \\
\text { (T. diophthalmus) over solid-orange-painted bugs; the } \\
\text { latter turned out to be cryptic to the predator. }\end{array}$ & $\begin{array}{l}\text { Fabricant \& } \\
\text { Herberstein, } \\
2015\end{array}$ \\
\hline $\begin{array}{l}\text { Mantodea \& } \\
\text { Passeriformes }\end{array}$ & $\begin{array}{l}\text { Wild birds and naïve chicks avoided aposematic harlequin } \\
\text { bugs (T. diophthalmus) but mantises (H. majuscule) } \\
\text { showed no aversion to them. }\end{array}$ & $\begin{array}{l}\text { Fabricant \& } \\
\text { Smith, } 2014\end{array}$ \\
\hline Hemi & $\begin{array}{l}\text { Aposematic caterpillars }(D \text {. casta) were attacked less by } \\
\text { assassin bugs (P. plagipennis) when they were in larger } \\
\text { aggregations. }\end{array}$ & $\begin{array}{l}\text { Reader \& } \\
\text { Hochuli, } 2003\end{array}$ \\
\hline $\begin{array}{l}\text { Hemiptera } \\
\text { and } \\
\text { Hymenoptera }\end{array}$ & $\begin{array}{l}\text { Assassin bugs (Pselliopus sp.) and paper wasps preferred } \\
\text { non-spined or lightly spined slug caterpillars. Wasps } \\
\text { showed decreasing response to prey with time and } \\
\text { experience. }\end{array}$ & $\begin{array}{l}\text { Murphy et al., } \\
2010\end{array}$ \\
\hline Coleo & $\begin{array}{l}\text { Three species of aposematic carabid beetles were attacked } \\
\text { more frequently than five non-aposematic carabid beetles } \\
\text { by } O \text {. olens (Coleoptera: Staphylinidae). }\end{array}$ & $\begin{array}{l}\text { Bonacci et al., } \\
2006\end{array}$ \\
\hline Coleoptera & $\begin{array}{l}\text { Ground beetles (C. pallipes) were more likely to attack } \\
\text { non-toxic rove beetles than toxic rove beetles (P.fuscipes) } \\
\text { due to higher levels of chemical defences. }\end{array}$ & $\begin{array}{l}\text { Tabadkani \& } \\
\text { Nowzari } \\
(2015)\end{array}$ \\
\hline Coleoptera & $\begin{array}{l}\text { Nematodes ( } H \text {. bacteriophora) produce olfactory based } \\
\text { aposematism to deter nocturnal foraging beetles ( } P \text {. } \\
\text { madidus) }\end{array}$ & $\begin{array}{l}\text { Jones et al. } \\
(2016)\end{array}$ \\
\hline
\end{tabular}




\section{Why consider other predator groups?}

The goal of this review is to not only to highlight the significance of invertebrate predators as a selective force on aposematic prey but also to reiterate the importance of investigating multiple, ecologically relevant predators for a holistic understanding of predator roles. When predators differ in foraging behaviour and preferences, they can exert different forms or directions of selection on prey phenotypes. A classic example of this is the selection on goldenrod galls by birds, that prefer larger galls (larger larvae, more profitable), and invertebrates, that prefer smaller galls (easier to parasitize or bore into). If both predators are present, goldenrod gall size undergoes stabilizing selection and an intermediate gall size confers the highest fitness. In addition, changes in the abundance of birds and invertebrates from year to year can affect the gall population for the following year (Abrahamson et al., 1989; Tscharntke, 1992).

The practice of considering more than one predator type (and its' subsequent behaviour) has been less prevalent in the study of animal coloration and aposematism as literature has continually focused on behaviour and cognition from a single perspective and far fewer studies have investigated other prey taxa. Fabricant and Smith (2014) discovered that aposematic Harlequin bugs were aposematic to domestic chicks but not to praying mantids (they also observed assassin bugs, lynx spiders, and orb-web spiders feeding freely on these bugs). Further, Pearson (1985) offered tiger beetles (Cicindela spp.) to birds, lizards, and robber flies to investigate which anti-predator defence (between colour, body size, chemical composition, flight, or gregariousness) was the most effective deterrent. They found that each predator differed in their prey preferences and that different combinations of deterrent were effective against different predators. Thus, considering a 
variety of ecologically relevant predators is essential to testing hypotheses about the evolution of prey phenotypes.

When investigating coloration in anti-predator defences, it is essential to consider how it will be perceived by the visual system of the intended predators. Terrestrial invertebrates exhibit a wide array of visual systems that can differ in structure, acuity, or specialization for various processes (e.g. detecting polarized light, dealing with high light intensities) (Kelber 2006; Land and Nilsson 2012) while the visual systems among birds are comparatively much less diverse (Hart and Hunt, 2007). Hence, invertebrates and birds could perceive or react differently to the same visual signals, which has implications on the type of predation pressure they impose. Animal coloration has been classically viewed through the human visual system and perspective but advances in visual ecology and technology has created opportunities to explore the importance of signals invisible to humans (Church et al., 1998) and signals from the perspective of potential predators. The perception of a signal plays a fundamental role in understanding how it functions and, in turn, how it evolved (Cuthill and Bennet, 1993). Invertebrates, as well as other ecologically relevant predators, should be further investigated as the current knowledge and theoretical work explaining and exploring aposematism is largely bird-focused and provides only a partial insight on the forms of predatory selection that prey defences undergo. It is important to explore a suite of predators and their visual systems if we are to obtain a comprehensive understanding of how they could shape prey phenotypes. 


\section{Conclusions}

Despite the diversity of predator species, behaviours, and visual systems, there is a generalized view of "predators" used in literature that is largely based on theoretical and empirical studies with birds. The lack of work on other predatory groups, specifically invertebrates, overlooks their roles on the shaping and evolution of prey defences. The form, function, and evolution of warning signals should be investigated with all ecologically relevant predator groups in mind to provide a comprehensive and integrated understanding. 


\title{
CHAPTER 2: PREY SIZE ALONG WITH PREDATOR SPECIES AND SEX INFLUENCES FORAGING DECISIONS IN A COMMUNITY OF ADULT DRAGONFLIES.
}

\begin{abstract}
Avian predators have been widely employed to understand the evolution of conspicuous signals in unprofitable prey, a phenomenon known as aposematism. However, insect predators are abundant, diverse, and highly visual foragers that have been shown to be capable of learned aversion. Therefore, it is quite possible that their behaviour also shapes the nature of anti-predator signals. First, I evaluated the responses of a community of adult dragonflies (Odonata) to artificial prey of varying size $(2.5-31 \mathrm{~mm}$ lengthwise $)$ and colour (black, black/yellow striped) and tested how the combination of prey colour and size affect prey survivorship. The relative attack rates of dragonflies on prey increased as prey size decreased, but there was no evidence that the attack rates by dragonflies were affected by prey colour and no evidence for an interaction between colour and size. Second, I compared the survivorship of black-painted prey presented to two common Libellulid dragonflies: Leucorrhinia intacta and the larger, Libellula pulchella. I found that prey survival differed between the dragonfly species and sexes, with $L$. pulchella more likely to attack a broader range of prey, and females were more likely to attack prey than males. Collectively, the results indicate that dragonflies are highly size selective. However, while the nature of this selectivity varies among dragonfly species, there is little evidence that they are deterred by classic black/yellow warning signals.
\end{abstract}




\section{Introduction}

Animal colouration is a key trait in anti-predator defences, allowing organisms to match their backgrounds for camouflage (Cott, 1940), to startle predators (Edmunds, 1974) and warn potential predators that they are inedible or otherwise costly to attack (Ruxton et al., 2004). This latter association between conspicuous coloration (generally interpreted as "warning signals", (Wallace, 1889)) and defence is known as aposematism (Poulton, 1890). Experiments on the cognition and behaviour of birds have long been used to help understand the ecology and evolution of these warning signals (Mappes et al., 2005; Skelhorn and Rowe, 2016). Yet many invertebrates - ranging from spiders to asilid flies are widespread, diverse, voracious insectivores, and often outnumber birds in a given area by an order of magnitude. Moreover, they have also been shown on various occasions to be capable of aversion learning, a major component in the evolution of warning signals and mimicry. For example, mantids can learn to avoid unpalatable aposematically coloured milkweed bugs (O. fasicatus) (Gelperin, 1968) and subsequently avoid palatable, conspecific mimics (Berenbaum and Miliczky, 1984). Likewise, visually driven hunting spiders, such as jumping and crab spiders, are capable of learned aversion (Taylor et al., 2014; Morris and Reader, 2016).

Given their capabilities, researchers have long postulated a role for invertebrate predators in shaping warning signals and mimicry in other invertebrates. Bates (1862) himself observed aposematic butterflies (Heliconidae) in the neotropic flying freely without persecution by an array of predators such as dragonflies, lizards, birds, and robber flies. Shelley \& Pearson (1978) noted that predatory robber flies attacked chemically defended tiger beetles with orange abdomens less frequently than tiger beetles with dark 
abdomens and suggested that they may be partially responsible for the evolution of warning signals in this species. Work with mantids (Mantodea) shows that they can learn from experience to avoid unpalatable prey and that learning time can be shortened using more conspicuous signals such as stripes (Bowdish \& Bultman, 1993) or high luminance contrast (Prudic et al., 2007). The nature of selection on prey that predators generate can be complex when prey experience a suite of predators, each with different preferences. Indeed, the variety of predator types and their potential differences in foraging behaviour towards aposematic prey can help explain the evolution of warning colouration and aposematic species (Endler and Mappes, 2004). These studies not only demonstrate the abilities of invertebrates to gather information on prey quality but also that they are at least theoretically capable of generating selection for unpalatable prey to evolve conspicuous signals.

Dragonflies (Odonata: Anisoptera) are generalist and opportunistic predators that feed on a large variety of aerial prey. They are major predators of Hymenoptera and Diptera (Corbet, 1999), groups rich with models and mimics, and their foraging behaviour and prey preferences could have important implications for the evolution of warning signals and mimicry in these groups. As Bates (1862) observed in his seminal contribution to the subject of mimicry, dragonflies show considerable diet selectivity in that that they do not always attack the prey items that they approach (see also Beatty 1951; Baird 1991). O'Donnell (1996) found that Neotropical dragonflies oriented towards wasps but rarely pursued them and suggested that such behaviour may potentially select for mimicry. Dragonflies are highly visual predators with eyes that are specialized for detecting motion, colour (visible and ultraviolet) and polarized light (Corbet, 1999; Yang and Osorio, 1996). 
Perched dragonflies are also able to discriminate the distance and trajectory to prey items and some have been shown to be highly size selective, attacking artificial prey no larger than their heads (Olberg et al. 2005). Only two studies conducted over a decade ago were the first to formally quantify the responses of individual dragonflies to natural and artificial prey in the field in the context of aposematism. Kauppinen \& Mappes (2003) evaluated the responses of the dragonfly Aeshna grandis to natural prey (black flies and wasps), warningly-coloured natural prey (painted flies and wasps) and artificial prey dangled in front of the predators using a fishing rod and line. After recording a variety of tactile and non-tactile responses of the dragonflies towards the prey the authors suggested that prey with wasp-like coloration are avoided more by $A$. grandis, so such patterns may confer a selective advantage against these and similar invertebrate predators. By contrast, in independent work presenting tethered natural and artificial prey to a range of dragonfly species, Rashed et al. (2005) concluded that while dragonflies showed a preference for attacking small prey over large prey, there was no compelling evidence to support the hypothesis that conspicuous signals protect small insect prey from attack by dragonflies. Considering these two conflicting results, whether dragonflies can act as a selective agent for the evolution of conspicuous colouration in prey remains uncertain.

In this experiment, I have expanded on previous work in two important ways. First, although Kauppinen and Mappes (2003) notably controlled for prey size and Rashed et al. (2005) contrasted attack rates on two prey sizes, I explored a much wider range of prey size. Second, I explored this range of prey sizes in two colours, black and black-yellow striped. Together, these additions allowed us to investigate prey size preferences, colour pattern preferences, as well as whether prey size and colour interact to provide protective 
benefits to prey against dragonfly predators. For example, it is conceivable that dragonflies preferentially avoid conspicuously marked prey but only when prey are a certain size. This form of size-dependant interaction has been observed in caterpillars where eyespots provided protective benefits on large caterpillars but increased detection in small caterpillars (Hossie and Sherratt, 2012). Likewise, Penney et al. (2012) showed that mimetic fidelity in hoverflies (Diptera: Syrphidae) increases with body size, implying that close mimicry is more important for large-bodied insects. Therefore, I have asked for the first time whether the relative attack rates of dragonflies on insect prey are mediated by an interaction between body size and colour of the prey.

In some systems, prey body size can interact with warning signals to increase signal efficacy (Gamberale and Tullberg, 1996, 1998; Hagman and Forsman, 2003; Hossie and Sherratt, 2012). I was interested in testing the protective benefits of all levels of this size and colour pattern combination against an invertebrate predator since such interactions have only been tested against avian predators (see Forsman and Merilaita 1999, Halpin et al., 2013 and references above). Although there have been no studies testing this interaction against invertebrate predators, work has been done with these predators investigating prey size preferences alone (Nentwig and Wissel, 1986; Rashed et al., 2005; Baum et al., 2014) and the effects of prey colouration alone (Bowdish and Bultman, 1993; Kauppinen and Mappes, 2003; Prudic et al., 2007; Taylor et al., 2014). I hypothesized that warning colouration (i.e. black-yellow stripes) would interact with body size to provide protective benefits to smaller prey that would otherwise be absent, while larger prey would be unfavourable regardless of colour. 
I also investigated whether the species of dragonfly influenced the preference for certain prey sizes since dragonflies vary inter-specifically in body size. Although there is some intraspecific variation in body size among dragonflies, much of the variation in size is inter-specific. Whilst dragonflies are generalist and opportunistic feeders, they need to hold and macerate their prey, and handling/feeding can be limited by their own body size. I classified the species tested within the community into broad size-class categories (small and large) to elucidate the role of dragonfly body size in mediating foraging preferences. Just as Olberg et al. (2005), I predicted that the maximum prey size preferred by dragonflies would be relative to their own body size due to handling constraints. In a more direct experiment, I also looked at two commonly occurring species, Leucorrhinia intacta (28-32 $\mathrm{mm}$; head to end of abdomen) and Libellula pulchella $(43-52 \mathrm{~mm})$, and their response to prey of two sizes ( 5 and $12 \mathrm{~mm}$ ). I predicted that L. pulchella, the larger of the two odonate species, would show a greater tendency to attack larger prey while $L$. intacta would attack only smaller prey. I also took the opportunity to test any potential sex differences in foraging given odonates are readily sexed based on colouration and/or genital organs. While different sexes can have different nutritive requirements and time budgets (e.g. territorial defence in males, maturing ovaries in females), I did not have an a priori expectation of a sexual difference in foraging preference.

\section{Methods}

I conducted two experiments: a dragonfly community prey choice experiment and a species-specific prey choice experiment. The experiments were conducted in East Field meadow (approx. 1 ha; 4432'29” N, 76²2'17’'W) near Queens University Biological 
Station, Ontario, Canada. All dragonflies were tested from 0900 to 1500 local time, on sunny days, with temperatures ranging from $13-30{ }^{\circ} \mathrm{C}$. Surveys of the dragonfly community were conducted every two weeks to monitor species composition and relative abundances. These surveys were performed by first walking the perimeter of the field then spiraling inwards, towards the centre, tallying the species of individuals observed perching as I walked.

\section{Community Prey Choice Experiment}

The community prey choice experiments were performed between 3 June - 3 July and from 17 July - 30 July 2015. To study the effects of prey size and colouration on predation, artificial prey were created by gluing two spherical beads of the same diameter together (loosely mimicking the shape of Hymenopteran/Dipteran prey) and painted using non-toxic acrylic paint (DecorArt Crafter's Acrylic paint in "Bright Yellow" and "Black")

(Fig. 2). Prey consisted of seven different sizes $(2.5,5,9,12,16,18$ and $31 \mathrm{~mm}$; lengthwise) and two colour treatments (black, and black and yellow). The black and yellow stripes were scaled such that prey of all sizes received 5 black stripes and 4 yellow stripes. However, the smallest size treatment $(2.5 \mathrm{~mm})$ could not be painted with stripes and was presented only in black. 

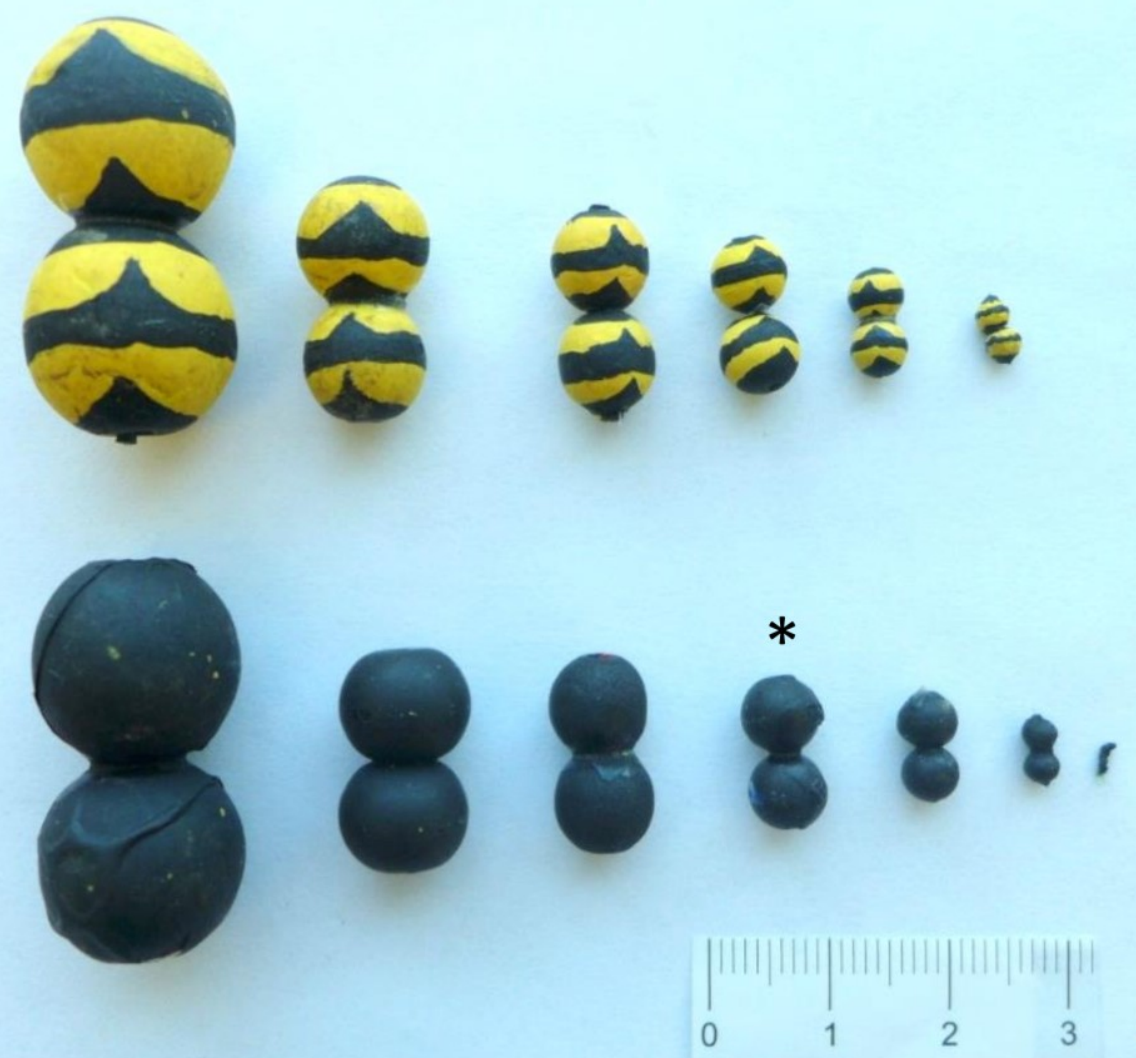

$\mathrm{cm}$

Figure 2. Artificial prey made from two conjoined beads, painted with acrylic paint in two colours (black and black/yellow striped) in various size treatments (2.5 (black only), $5,9,12,16,18$, and $31 \mathrm{~mm})$. The standard bead used in each pairwise presentation is denoted $(*)$. 
The reflectance of paints was measured using the Ocean Optics USB 2000 spectrophotometer (Dunedin, Florida, U.S.A.). Spectra were measured and calibrated against a 98\% white standard (Labsphere). The peak reflectance for yellow was around 570 $\mathrm{nm}$, which was lower than previously recorded for vespid wasps (see Kauppinen and Mappes, 2003 and Rashed et al., 2005) and the paint contained very low levels of UV reflectance (Fig. A1).

Artificial prey were presented on a pairwise $183 \mathrm{~cm}$ long Y-shaped rod made of bamboo (each prong was $53 \mathrm{~cm}$ long). Prey were hung $100 \mathrm{~cm}$ from the ends of each prong using dark green Power Pro microfilament braided fishing line $(10 \mathrm{lb}$ test; Innovative Textiles). Treatment prey were always presented pairwise with a standard bead (black 12 $\mathrm{mm}$ bead). To prevent potential side bias, the standard bead was alternately tethered on each prong with each presentation. This standard bead was introduced to facilitate preference standardization: the emergence times of dragonfly species did not completely overlap and with inevitable seasonal changes in environmental conditions (such as temperature and wind speed) it was appropriate to compare the number of attacks on a given prey type with the number of attacks against a constant standard model. This approach gives a relatively more direct measure of the nature of preference for one phenotype over another. To present the beads, I first located a perched dragonfly, approaching it slowly while holding the rod $2-3 \mathrm{~m}$ above the ground. The beads were then hung approximately $0.5-1.5 \mathrm{~m}$ above the dragonfly and moved in a manner that mimicked natural prey movement (i.e. side to side as if flying across the field of vision). Dragonflies were given a maximum of four minutes to respond. When a prey item was attacked (i.e. the dragonfly made direct physical contact with the bead), the type of bead 
(standard or treatment) as well as its size and colour were recorded. After an attack occurred, the dragonfly was caught and marked with two small dashes on the hind wing using a permanent marker, which prevented re-testing the same dragonfly. The sex and species of all tested dragonflies were identified and recorded. The rate of re-encounter with dragonflies that had already been tested was extremely low ( 2 re-encounters of 1153 total presentations) as the density of dragonflies was extremely high. If the dragonfly did not attack after the allotted time, it was caught and marked in the same manner.

In addition to the analysis of the whole community, I wanted to evaluate the broad scale patterns of foraging responses of dragonfly species in relation to their body size. The foraging preferences of thirteen species of dragonflies were evaluated (Table 2). Species were classified into small (Leucorrhinia intacta, Celithemus elisa, Celithemus eponina, Leucorrhinia. glacialis, Sympetrum spp., Epitheca cynosura, Leucorrhinia frigida, and Pachydiplax longipennis) and large (Libellula julia, Libellula quadrimaculata, Libellula luctuosa, Gomphus spicatus, and Libellula pulchella) size-class categories for total body length based on Jones et al. (2008). I tested whether there were differences in attack frequency or size preference for given prey types that could be explained by differences in body size of predator by fitting a generalized linear model (see below). 
Table 2. Summary of species included in the community choice experiment analyses, relative total body length (head to abdomen tip), given size-class category, and the number of individuals tested.

\begin{tabular}{|c|c|c|c|}
\hline Species & Length (mm) & Size Class & Number of individuals tested \\
\hline Leucorrhinia intacta & $29-33$ & S & 177 \\
\hline Celithemus elisa & $24-34$ & S & 132 \\
\hline Sympetrum spp. & $24-31$ & S & 9 \\
\hline Leucorrhinia frigida & $28-32$ & S & 1 \\
\hline Pachydiplax longipennis & $28-41$ & S & 1 \\
\hline Leucorrhinia. glacialis & $34-37$ & S & 94 \\
\hline Celithemus eponina & $36-42$ & L & 2 \\
\hline Epitheca cynosura & $37-44$ & L & 90 \\
\hline Libellula julia & $38-45$ & L & 229 \\
\hline Libellula quadrimaculata & $39-48$ & L & 104 \\
\hline Libellula luctuosa & $42-50$ & L & 99 \\
\hline Gomphus spicatus & $46-50$ & L & 194 \\
\hline Libellula pulchella & $52-57$ & L & \\
\hline
\end{tabular}

Notes: $\mathrm{S}=$ small species category; $\mathrm{L}=$ large species category; the number of individuals tested represents the amount of pair-wise presentations made to an individual dragonfly, regardless of whether they attacked or not. 


\section{Species-Specific Choice Experiment}

To test for potential inter- and intra- specific (sex-based) variation in response to prey size, I presented two sizes of black artificial prey (5 and $12 \mathrm{~mm}$ total length) separately to two species of co-occurring, co-generic dragonflies, namely Leucorrhinia intacta and Libellula pulchella (29-33 and $52-57 \mathrm{~mm}$ lengthwise, respectively). I chose these two species because they exhibit clear body size differences and both were readily abundant during the experimental period. This experiment was conducted from July 3 - 17 of 2015, a time at which these species overlap in flight period. They were tested in temporal blocks (cycling through the 2 species and 2 prey sizes in random order). Prey were hung $100 \mathrm{~cm}$ from a $183 \mathrm{~cm}$ long, straight bamboo pole. Unlike the pair-wise presentation in the previous experiment, these beads were offered singularly because rather than comparing prey treatments, I wanted to measure single prey survivability. Moreover, there was less need to standardize because the experiments were conducted over a relatively short period of time and used a randomized block design, with block taking up variation in relevant environmental conditions such as temperature and wind speed.

I walked the perimeter of the field until one of the target species was located and prey were offered for a maximum of 120 seconds. I measured the latency from the presentation of the prey until either the dragonfly attacked, did not attack but stayed perched for the allotted time or flew away before the end of the allotted time. Sex was also recorded for all tested dragonflies. Given the high abundance of both species and the low re-encounter rate in the community experiment (see above), tested individuals were not marked. 


\section{Statistical Analysis}

Given the binary nature of the response variable in the community preference tests (the dragonflies attacked either the treatment prey or standard prey), I first fitted a generalized linear model assuming binomial error (i.e. a logistic regression model). This model treated prey size (as a continuous variable), colour (categorical), and their interaction, as predictors. To compare the attack rates (proportion of attacks on treatment bead) of different dragonfly size classes (two levels) I re-fitted a logistic regression model that included dragonfly size class as a fixed factor (since there were only two levels), with all but the highest order ( 3 way) interaction. This enabled me to elucidate how the probability of attacking the treatment bead might vary with prey size (continuous), prey colour (categorical), and dragonfly size (categorical) as well as how the effect of prey colour might vary with prey size (via pairwise interactions).

I fitted a Cox proportional hazards model using coxph function from the "survival" package to investigate whether dragonfly species, dragonfly sex, temporal block and prey size influence the time to attacking prey in the species-specific experiments. Three types of endpoints were recognized in this survival analysis. First, if the dragonfly attacked the bead, I noted its latency to attack in seconds. Second, if the dragonfly flew away before the allotted time, the time at which observations ceased was recorded (a censored data point). Finally, if the dragonflies did not attack the offered bead after the 120 seconds and stayed perched then the event was considered right censored. The time to event analysis considered species, sex, bead size, and each of their two-way interactions as categorical predictors. All statistical analyses were conducted using R v. 3. 1.3 (R Development Core Team, 2010). 


\section{Results}

Community Prey Choice Experiment

A total of 1153 dragonflies were presented with a pairwise choice. $46 \%$ of the dragonflies tested made an attack and of the prey attacked, overall $48 \%$ and $52 \%$ attacked the standard and treatment bead, respectively. Prey size was a strong determinant as to whether dragonflies attacked the treatment bead, since the smaller the treatment prey, the more likely they were to be attacked $\left(\chi^{2}{ }_{1}=281.583, \mathrm{P}<0.001\right)$. However, there was no effect of prey colour on dragonflies' attack decisions $\left(\chi^{2}{ }_{1}=0.415, \mathrm{P}=0.519\right)$ and no evidence for an interaction $\left(\chi^{2}{ }_{1}=0.656, \mathrm{P}=0.418\right)$. Thus, the probability of a treatment bead being attacked by dragonflies increased as prey size decreased (Fig. 2), regardless of colour.

When evaluating the attack rates of dragonflies on the standard bead and beads of different size classes, prey size $\left(\chi^{2}{ }_{1}=80.816, \mathrm{P}<0.001\right)$ and dragonfly size class $\left(\chi^{2}{ }_{1}=\right.$ 13.417, $\mathrm{P}<0.001)$ significantly affected the response of dragonflies such that smaller dragonflies only attacked prey up to $12 \mathrm{~mm}$ but larger dragonflies attacked across the range of prey sizes (Fig. 3). The interaction between prey size and dragonfly size class also had a significant effect on attack response $\left(\chi^{2}{ }_{1}=6.154, \mathrm{P}=0.013\right)$ (Fig. A2). Prey colour and its interaction with prey size and dragonfly size class were again not found to be significant (Table 3). 


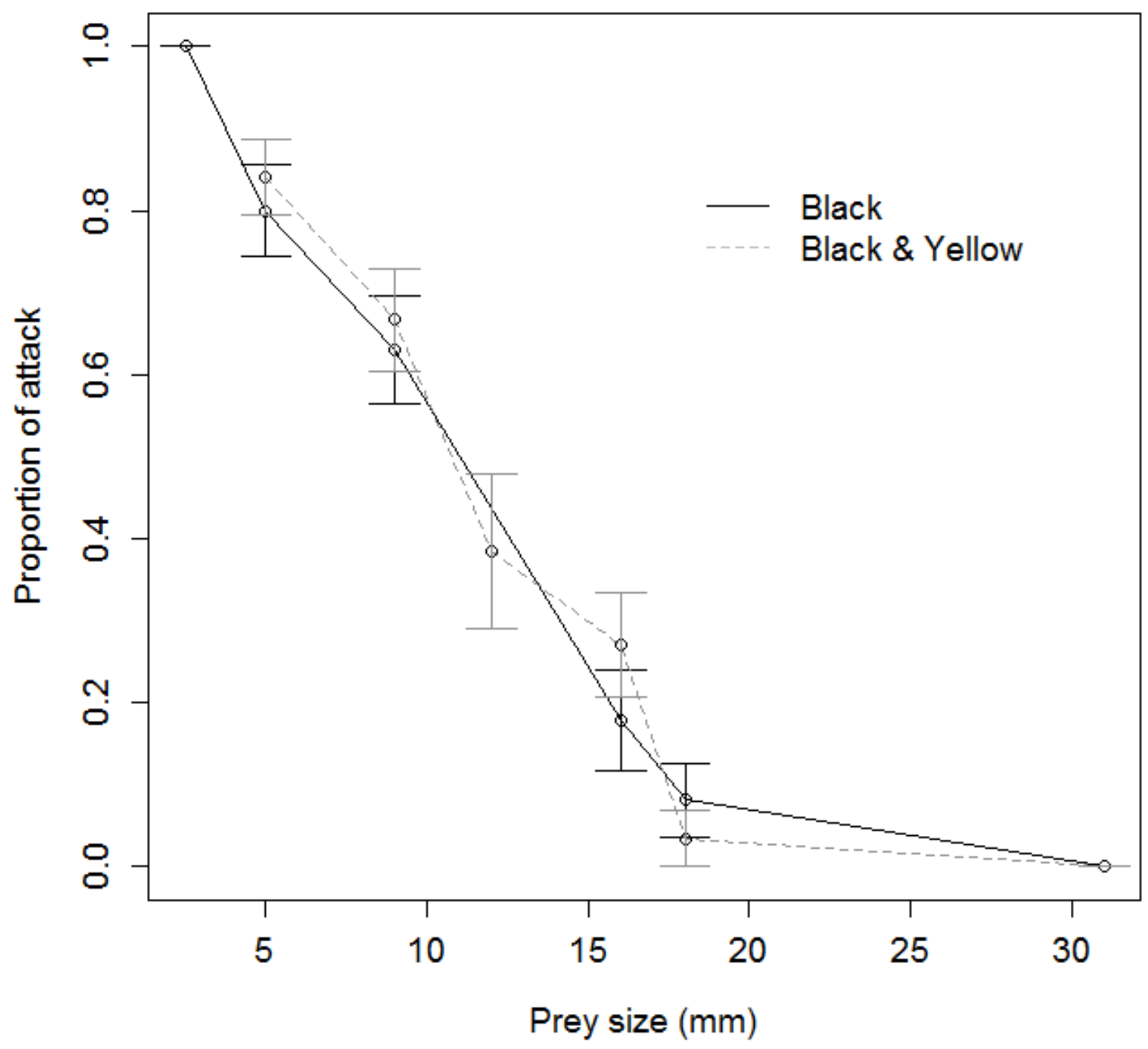

Figure 3. The proportion of attacks on treatment beads (compared to standard bead) by a community of adult dragonflies on prey of varying size (2.5 (black only), 5, 9, 12, 16, 18, and $31 \mathrm{~mm}$ ) in two colours (black and black/yellow striped). Error bars show the binomial $95 \%$ confidence intervals. 


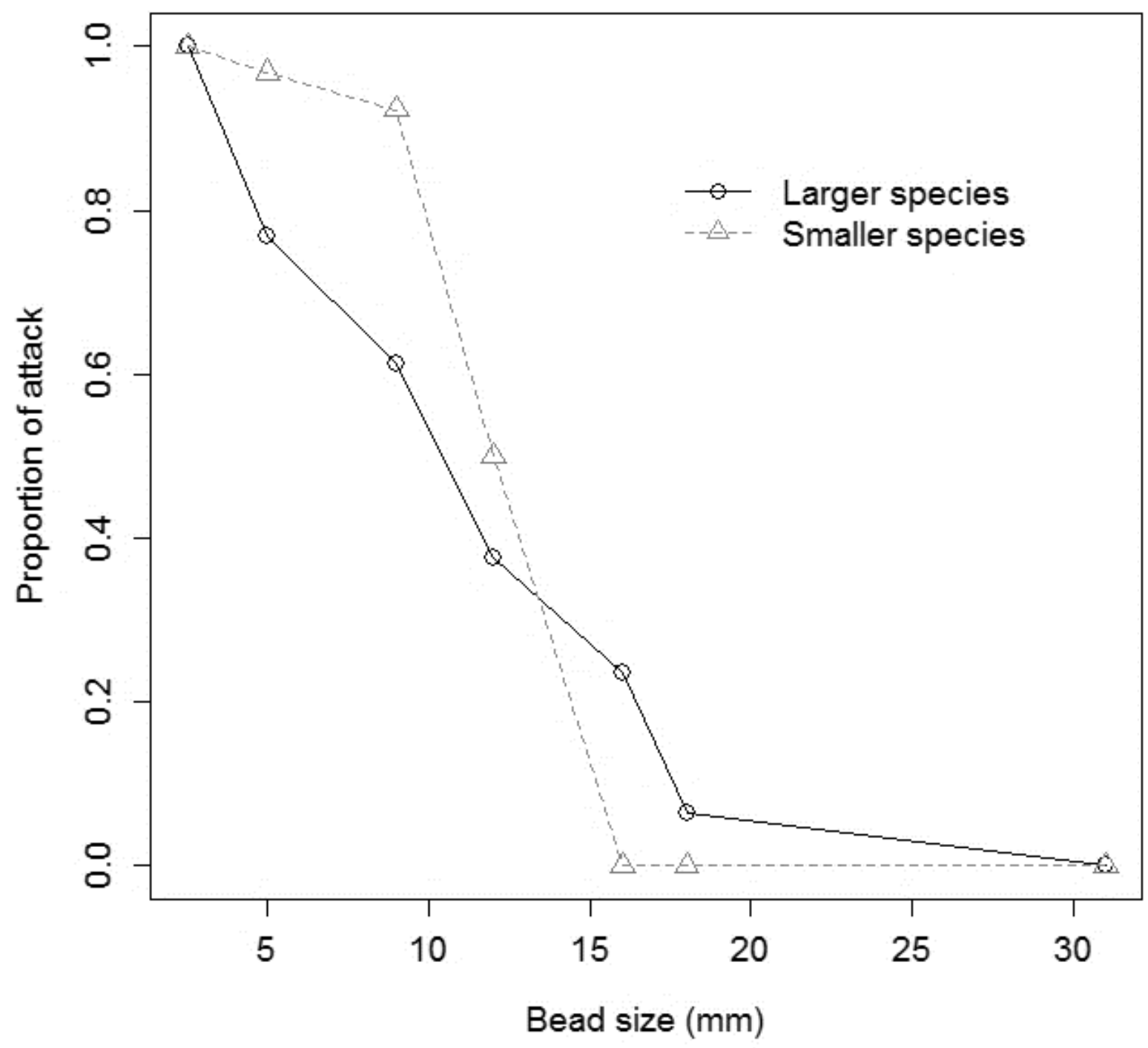

Figure 4. The probability of attack on treatment bead (compared to standard bead) by smaller dragonflies (C. elisa, C. eponina, L. intacta, L. glacialis, Sympetrum spp., E. cynosura, L. frigida, P. longipennis) versus larger dragonflies (L. quadrimaculata, $G$. spicatus, L. pulchella, L. julia, and L. luctuosa) on prey of varying size (2.5 (black only), $5,9,12,16,18$, and $31 \mathrm{~mm}$ ) for both colour treatments. 
Table 3. ANOVA results of a binomial logistic regression testing for the effects of prey size, prey colour, dragonfly size class, and their interactions on the proportion of treatment prey attacked in the community choice experiment. Shown are the final model equation, the model's parameters, chi-squared values, degrees of freedom, $\mathrm{p}$-values for each variable.

\begin{tabular}{|c|c|c|c|}
\hline \multicolumn{4}{|c|}{$\begin{array}{l}\text { Model (as specified in } R): \operatorname{glm}\left(\left(\operatorname{cbind}\left(C \_f r e q, T \text { freq }\right)\right)\right. \\
\sim \text { Size*Colour*D_size }- \text { Size:Colour:D_size, family=binomial) }\end{array}$} \\
\hline Explanatory Variables & $\chi^{2}$ & $\begin{array}{l}\text { Degrees of } \\
\text { freedom }\end{array}$ & $\mathrm{P}$-value \\
\hline Size & 80.816 & 1 & $<0.001$ \\
\hline Colour & 0.009 & 1 & 0.924 \\
\hline D_size & 13.417 & 1 & $<0.001$ \\
\hline Size*Colour & 0.239 & 1 & 0.625 \\
\hline Size*D Size & 6.154 & 1 & 0.013 \\
\hline Colour*D_Size & 0.184 & 1 & 0.668 \\
\hline
\end{tabular}

Notes: cbind(C_freq,T_freq) $=$ the proportion of attacks on the treatment bead versus the controlled bead; Size = prey size; Colour = prey colour; D_Size = dragonfly size class; Significant P-values are shown in bold $(\mathrm{p} \leq 0.05)$. 


\section{Species-Specific Choice Experiment}

A total of 49 attacks from 131 presentations were made by dragonflies. $76 \%$ of attacks were made by females, of both species, and but $60 \%$ of all presentations were to females (Table 4). The probability of prey being attacked after presentation was lower overall against Libellula pulchella than Leucorrhinia intacta $\left(\chi_{1}^{2}=9.4285, \mathrm{P}=0.0021\right)$, as L. pulchella attacked both prey sizes while L. intacta mainly attacked $5 \mathrm{~mm}$ prey (Fig. 5). Attack rates on prey were also affected by prey size $\left(\chi^{2}{ }_{1}=33.5264, \mathrm{P}<0.001\right)$ and sex of dragonfly $\left(\chi^{2}{ }_{1}=7.2073, \mathrm{P}=0.0072\right)$. Unlike the community experiment, the interaction between dragonfly species and the size of prey on time to attack was not significant $\left(\chi^{2}{ }_{1}=\right.$ 9.4285, $\mathrm{P}=0.0678)$. 
Table 4. Number of prey presentations and attacks made by females and males of Leucorrhinia intacta and Libellula pulchella.

\begin{tabular}{|l|c|c|c|c|}
\hline \multirow{2}{*}{ Gender } & \multicolumn{2}{c|}{ Female } & \multicolumn{2}{c|}{ Male } \\
\cline { 2 - 5 } & Offered & Attacked & Offered & Attacked \\
\hline Leucorrhiniaintacta & 41 & 15 & 34 & 4 \\
\hline Libellula pulchella & 38 & 22 & 18 & 8 \\
\hline
\end{tabular}

Notes: Offered $=$ artificial prey of either 5 or $12 \mathrm{~mm}$ were presented and dragonflies were allotted $120 \mathrm{~s}$ to attack. Attacked = the dragonfly made physical contact with the offered artificial prey. 

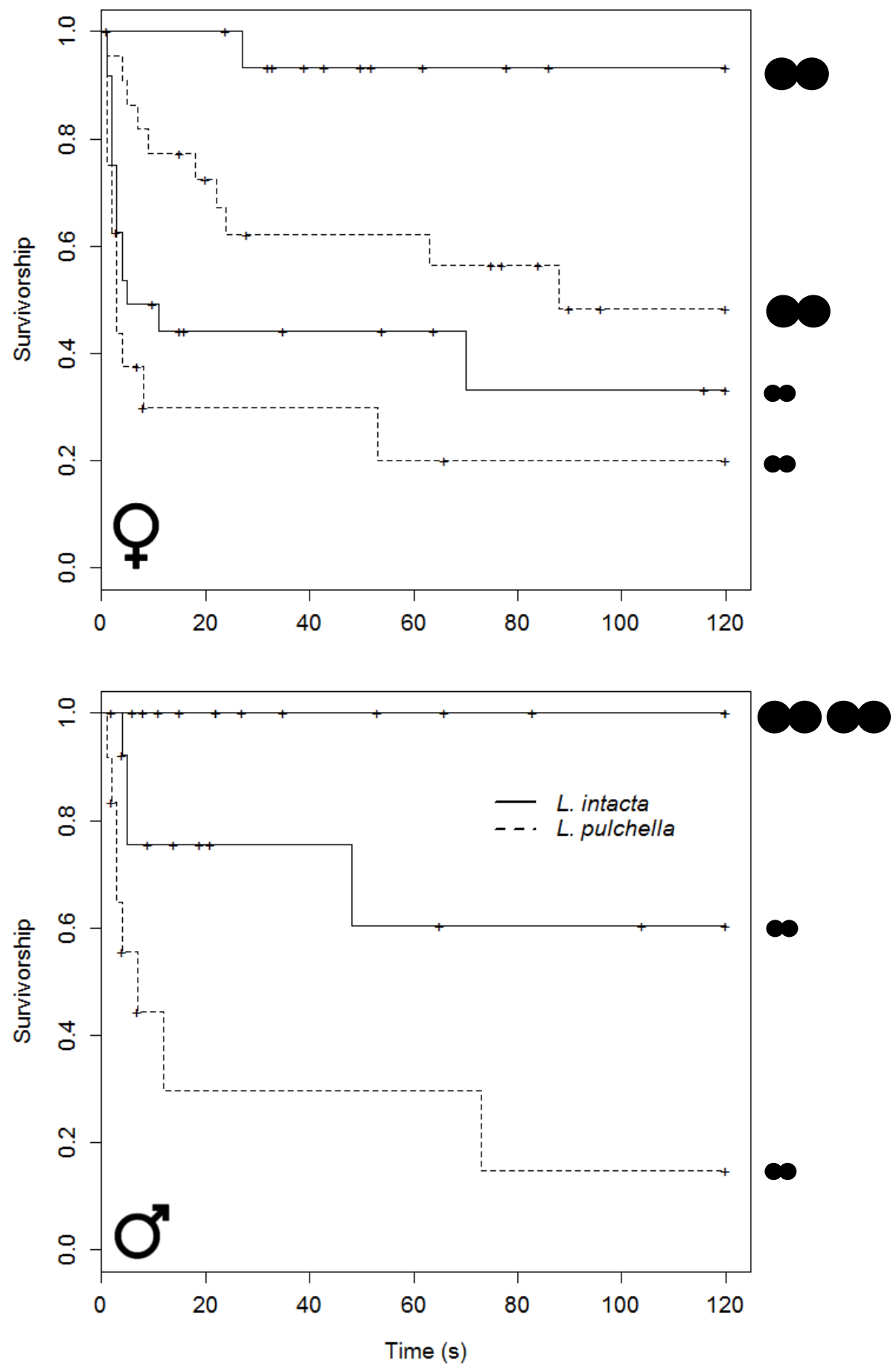

Figure 5. Cumulative survivorship curves (probability of survival) for prey (5 and $12 \mathrm{~mm}$; lengthwise) against female (top) and male (bottom) dragonflies of two species (Leucorrhinia intacta and Libellula pulchella). Censored observations are denoted by "+”. Large prey were not attacked by males of either species thus survival lines are overlapping at 1.0 . 


\section{Discussion}

The aim of this study was to investigate the foraging choices of dragonflies in relation to the colour and size of presented prey. Overall, dragonflies preferred smaller prey and there was a significant interaction between predator and prey size, in that smaller dragonflies tended to attack prey up to $12 \mathrm{~mm}$ in length while larger dragonflies attacked across the range of prey sizes presented. The species-specific experiment further supported these results, as L. intacta, the smaller species of the two tested, attacked primarily small prey. In addition, female dragonflies were more likely than males to attack prey. Together, the results suggest that smaller prey are strongly preferred by this community of dragonflies but that they exhibit no preference for black over black-yellow prey of any given size.

The conclusion that prey colour was not a key feature in deterring dragonfly attacks is consistent with the results of Rashed et al. (2005). With the expansion of this design to cover a range of prey size treatments in two different colour patterns I was also able to rule out a potential interaction between prey colour pattern and size. It is likely that colour cues are primarily used in conspecific identification and communication since odonates exhibit a wide variety of colouration and patterning that can vary intra- and inter-specifically (Bybee et al., 2012; Guillermo-Ferreira et al., 2015). "Percher" dragonflies have specialized ommatidia on the dorsal portion of their eye which allows them to see prey against a bright sky backdrop (Hisada et al., 1965), but it is conceivable that if prey were flying at lower angles that colour detection is possible. It is likely that prey size, shape, and movement are more decisive factors for foraging dragonflies. On various occasions, dragonflies have been observed to avoid aposematic prey but it is apparent that this 
behaviour is not driven by colouration (but potentially by other factors such as aposematic prey that use additional morphological defences - see Appendix A). In addition, it implies there is relaxed selection on colouration among smaller prey, which could potentially explain why there is low mimetic fidelity among smaller mimics (Penney et al., 2012).

Predator body size can also be a strong determinant of prey size preferences because of handling constraints or gape limitations (Hansen et al, 1994; Symondson et al., 2002), which can in turn influence foraging decisions. Invertebrate raptorial feeders are known to have preferences for specific prey sizes (Iwasaki, 1990; Baum et al., 2014) and I decided to investigate this preference in dragonflies as their feeding behaviour is similar. As predicted, dragonflies overall preferred smaller prey but I was also able to show that the range of prey attacked is relative to the size of dragonfly. Smaller dragonflies were limited to a smaller range of prey sizes, which is likely due to handling constraints. These results are especially interesting considering the turnover of species that occurs in this area. Based on observations of dragonfly species composition during the experiment, medium-large species were more prominent early in the season while smaller species were dominant later in the season. Thus, changes in dragonfly species composition could also mean changes in selection pressure on a range of prey sizes.

In the species-specific choice experiment, females attacked more frequently than males when offered prey ( $76 \%$ vs $24 \%$ ) and females tended to attack larger prey. To date, very little work has been done on sex-based preferences in foraging in dragonflies. It is possible that the differences I observed in the experiment are due to reproductive differences. For example, during and around the time of reproduction in adult dragonflies, males and females can differ in the primary energy allocations that are dictated by their 
relative reproductive roles. Prior to sexual maturity in adults, weight gain and energy assimilation in females is focused on ovarian maturation and thoracic flight muscles (to search for suitable oviposition sites) whereas males solely dedicate their weight gain to thoracic flight muscles, likely necessary for territoriality, mate searching, and/or mate guarding (Corbet, 1999). In turn, these differences can alter foraging behaviour and preferences such as the ones I observed (i.e. increased foraging rates, preference for larger prey). Sex-based differences can also vary between species; in pre-reproductive stages, males of Pachydiplax longipennis and L. pulchella in enclosures gained more weight than females (Dunham 1992a; Marden, 1995a) but in an analysis of 54 species (8 families), Anholt et al. (1991) found that on average males and females gained $84 \%$ and $125 \%$ respectively, of their original body weight during maturation. In this study, it is likely that a range of dragonflies from varying adult life stages - post-emergence, pre- reproductive, reproductive, and post-reproductive - were tested and it would be difficult to test the effect of life stage on prey preference using the data. However, the results give a coarse measure of how prey preferences can be influenced by predator sex in two species of different sized dragonflies.

This study highlights that dragonflies selectively forage for smaller prey but do not differentiate between black and black-yellow prey, regardless of their size. In testing a preference for differently patterned prey across a broader range of prey sizes, this study extends previous work on dragonfly foraging in the context of warning colouration (Rashed et al., 2005; Kauppinen and Mappes, 2003) and provides further insight on the foraging preferences and behaviour of a prominent aerial invertebrate predator. I conclude that dragonflies are unlikely to play a significant role in selecting for visual warning signals 
since they do not affect predation. Nevertheless, an increase in size provides protective benefits. If dragonflies are a selective force on aposematic prey, it may be due to other prey features such as distastefulness, aggressive behaviour, morphological protection (i.e. hardened, leathery cuticle) that occur after capture, as I occasionally witnessed dragonflies catching natural prey but dropping them after sampling, indicating the potential for tasterejection behaviour (Appendix A). I also showed that there are distinct foraging differences between male and female dragonflies although what drives these differences remains unknown. The prey community is subject to a variety of predators, invertebrates and vertebrates, that will vary in their foraging behaviour and preferences. Learning about these differences will provide us with a comprehensive understanding of the variety of selective pressures that can drive the evolution of anti-predator strategies. Although I found that colur is not a key determinant of the foraging preferences of dragonflies, other invertebrates such as mantids and hunting spiders have been shown to use a variety of visual cues to distinguish unpalatable prey (Bowdish \& Bultman, 1993; Taylor et al., 2014) and would be an ideal system for future work to further investigate the interaction between prey body size and warning signal efficacy. 


\section{APPENDICES \\ Appendix A: Determining prey preference of dragonflies through hand-feeding. Introduction}

While conducting the community choice experiment, I observed interesting behaviours by foraging dragonflies. I witnessed a dragonfly capture a lady bird beetle, inspect or attempt to feed on it, and then drop it without consuming it. I also observed dragonflies avoiding various prey such as paper wasps (Hymenoptera: Vespidae), Virgin Tiger Moths (Lepidoptera: Arctiidae: Grammia virgo), Eastern Tiger Swallowtail butterflies (Lepidoptera: Papilionidae: Papilio glaucus). Although this aversion is likely based on prey size, I have continuously observed adult dragonflies feeding on conspecifics that are equal or larger than themselves. As dragonflies are main predators of aerial insects (e.g. Diptera and Hymenoptera), it is likely that generate a form of selection on such insects, which I assume is not driven by prey colour.

Koch et al. (2014) successfully increased dragonfly survival within outdoor enclosures by hand-feeding them fruit flies. I used this method to investigate whether dragonflies would feed on any type of prey given the opportunity.

\section{Methods}

The experiment was conducted from May 30 to June 11 from 2016 in East Field meadow (approx. 1 ha; 4432’29” N, 76²2’17” W) near Queens University Biological Station, Ontario, Canada. All dragonflies were tested from 0900 to 1500 local time on sunny days, with temperatures ranging from $13-25^{\circ} \mathrm{C}$. 
I used a malaise trap to collect live prey items (mainly insects) naturally available to the community of dragonflies. Traps were set up at 0900 and emptied at 1500 on the first day of the experiment. Insects were stored in a fridge at $10{ }^{\circ} \mathrm{C}$. I chose a variety of insects of different taxonomic Orders and sizes. I identified the prey as accurately as possible (to the species, if possible) and unknown prey were photographed and recorded for further processing. Prey were weighed (Mettler Toledo AE 100), numbered, and then stored in $1 \mathrm{~mL}$ plastic centrifuge tubes.

Rather than randomly catching dragonflies with a sweep net, I chose to dangle artificial prey to perched dragonflies to assess whether they were foraging at the time or not. If the dragonfly attacked the artificial prey, I subsequently caught it with a sweep net and stored it in a $50 \times 50 \mathrm{~cm}$ mesh enclosure. Dragonflies were handled by folding back their wings in between two fingers. I extracted the live prey items from the tubes using tweezers and offered them to prey by holding the prey items to their mandibles. Dragonflies would either (a) push away the prey items with their front legs with inspection (rejection), (b) inspect the prey with their mandibles but not feed on them (rejection), or (c) inspect the prey with their mandibles and begin feeding on them (accept). Dragonflies were fed a maximum of four prey and were not offered subsequent prey if they started feeding. If dragonflies did not feed wholly on prey, discarded remains were collected and weighed at the end of the day.

\section{Pre-analyzed quantitative and qualitative data}

I made a total of 419 offers to 141 dragonflies. Of the 141, 92 dragonflies eventually started feeding on an offered prey and of these dragonflies, 66 and 26 were female and males, respectively. Four main prey types were fed on (Table A1). The aerial prey 
community in this area was abundant in Diptera, Hymenoptera, Odonata, and Lepidoptera. Tabanidae, Sarcophagidae, Syrphidae, and Muscidae (all Diptera) were common and abundant. One of the most common Hymenopterans were sweat bees (Halictidae).

Hymenoptera were often rejected by dragonflies unless they were able to break the cuticle. Dragonflies also did not feed on a variety of beetles such as lady bird (Coccinellidae) and jewel beetles (Buprestidae). 
Table A1. Frequency of different prey types (Diptera, Hymenoptera, Hemiptera, Lepidoptera) fed on by dragonflies and the frequency of female and males dragonflies that accepted prey. A total of 92 feeding events occurred.

\begin{tabular}{|c|c|c|c|c|}
\hline & \multicolumn{4}{c|}{ Feedings (n=92) } \\
\hline Prey Types & Diptera & Hymenoptera & Hemiptera & Lepidoptera \\
\hline & 75 & 14 & 1 & 2 \\
\hline \multicolumn{3}{|c|}{ Female } & \multicolumn{2}{c|}{ Male } \\
\hline Sex & 66 & \multicolumn{2}{c|}{26} \\
\hline
\end{tabular}




\section{Appendix B: Additional figures}

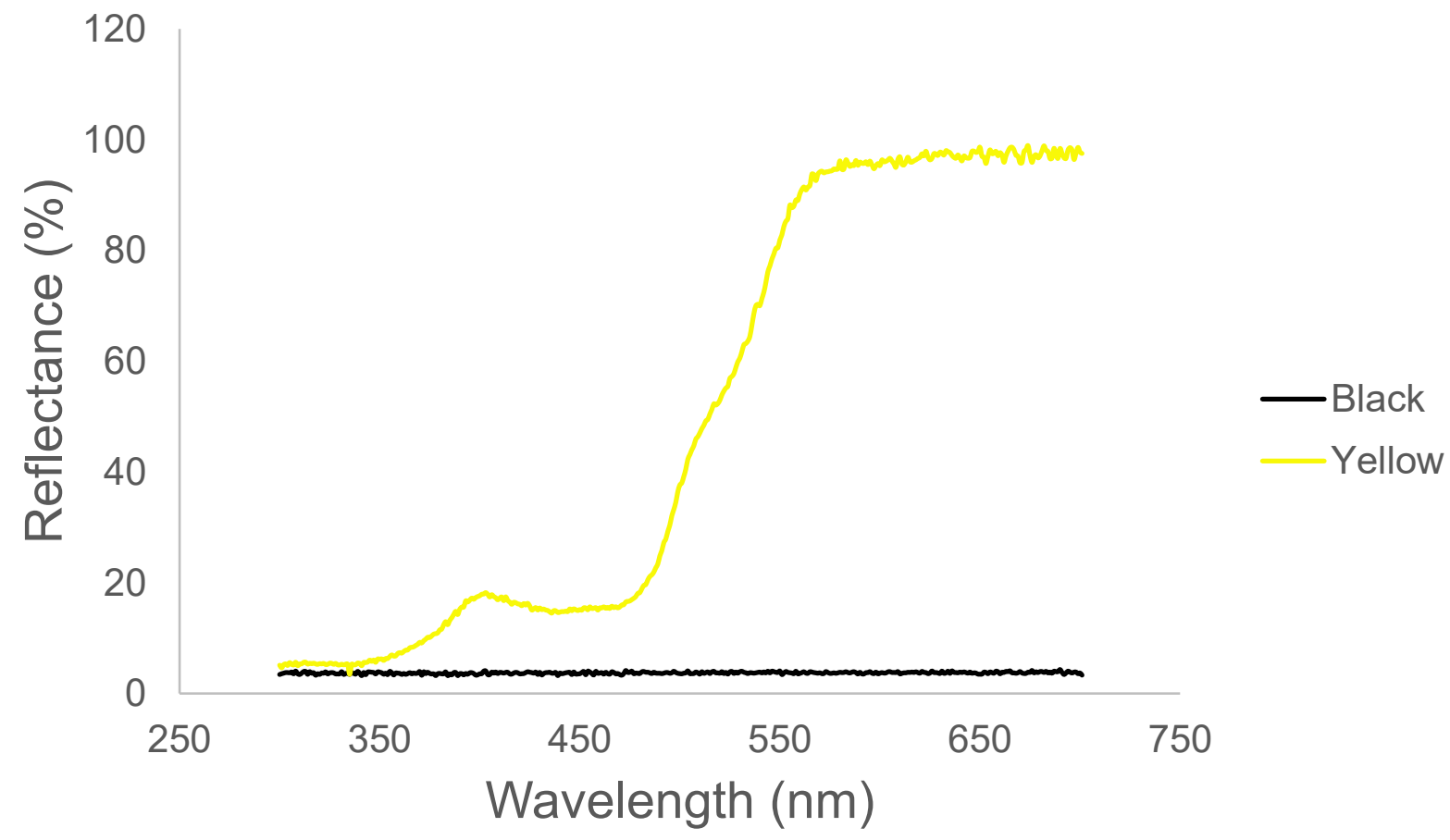

Figure A 1. Spectral curves for the black and yellow paint used to create the artificial prey. 


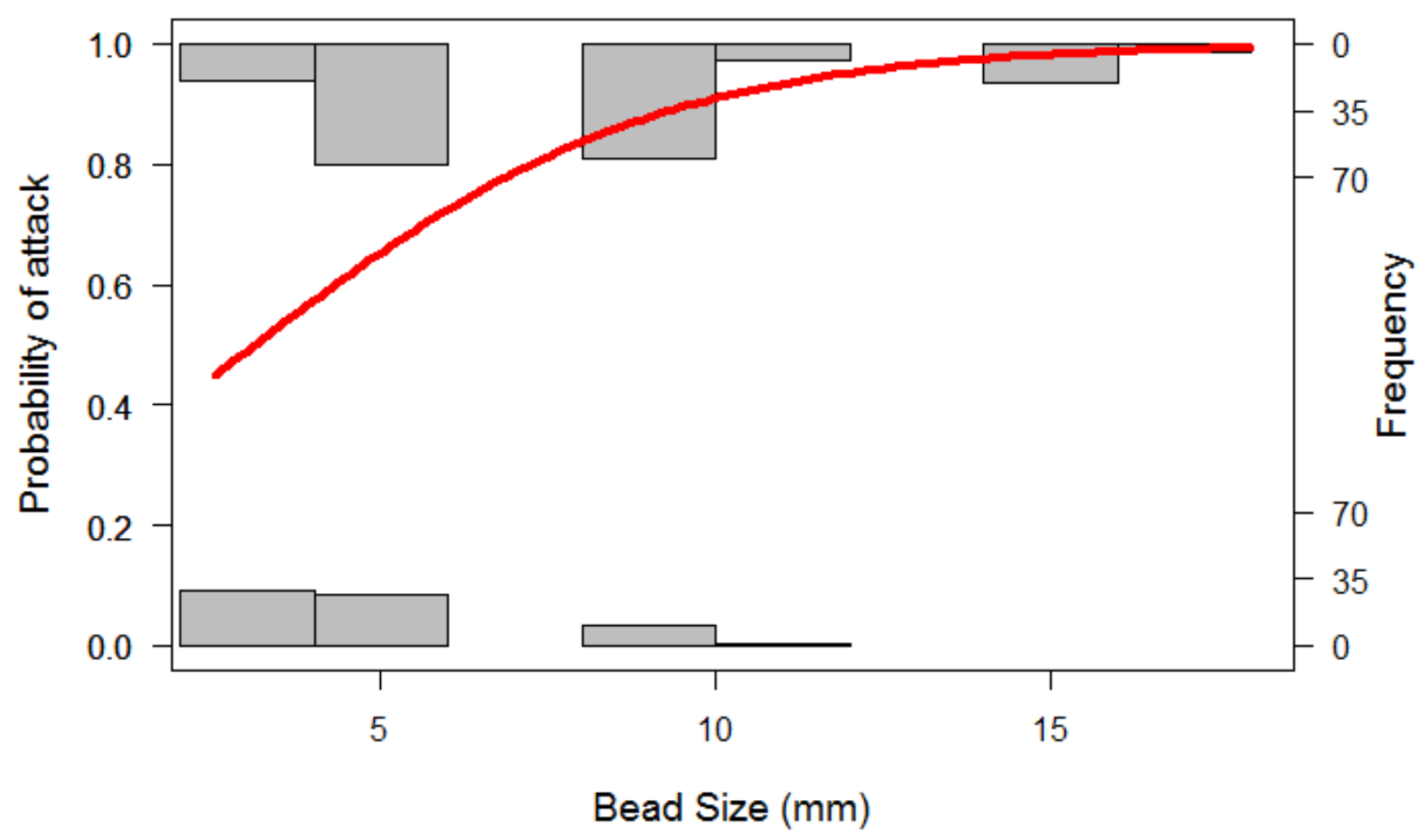

Figure A 2. The probability of attack on treatment bead (compared to standard bead) by smaller dragonflies (0; C. elisa, C. eponina, L. intacta, L. glacialis, Sympetrum spp., E. cynosura, L. frigida, P. longipennis) versus larger dragonflies $(1 ;$ L quadrimaculata, $G$. spicatus, L. pulchella, L. julia, and L. luctuosa) on prey of varying size (2.5 (black only), $5,9,12,16,18$, and $31 \mathrm{~mm}$ ) for both colour treatments and the frequency of attacks. 


\section{REFERENCES}

Abrahamson, W. G., Sattler, J. F., McCrea, K. D., \& Weis, A. E. (1989). Variation in selection pressures on the goldenrod gall fly and the competitive interactions of its natural enemies. Oecologia, 79, 15-22.

Ang, H. P., \& Newman, L. J. (1998). Warning colouration in pseudocerotid flatworms (Platyhelminthes, Polycladida). A preliminary study. Hydrobiologia, 383(1-3), 29-33.

Anholt, B. R. (1991). Measuring selection on a population of damselflies with a manipulated phenotype. Evolution, 1091-1106.

Baird, J. M. (1991). Behavioural ecology of foraging in Pachydiplax longipennis (Odonata: Libellulidae). Journal of Insect Behavior, 10, 655-678.

Bajger, J. (1980). Diversity of defensive responses in populations of fire toads (Bombina bombina and Bombina variegata). Herpetologica, 133-137.

Bates, H. W. (1981). Contributions to an insect fauna of the Amazon valley (Lepidoptera: Heliconidae). Biological Journal of the Linnean Society, 16(1), 41-54.

Baum, T., Katsman, I., Rivlin, E., Broza, M., Moshkovich, M., \& Katzir, G. (2014). Response of the Praying Mantis, Sphodromantis Viridis, to Target Change in Size and to Target Visual Occlusion. Journal of insect behavior, 27(3), 333-345.

Beatty, G. H. (1951). Odonate bionomics: I. Notes on the food of dragonflies. 1. Odonata vs. ants and bees. Bulletin of Brooklyn Entomological Society, XLVI, 29-37. 
Berenbaum, M. R., \& Miliczky, E. (1984). Mantids and milkweed bugs: efficacy of aposematic coloration against invertebrate predators. American Midland Naturalist, 64-68.

Bonacci, T., Aloise, G., Brandmayr, P., Brandmayr, T. Z., \& Capula, M. (2008). Testing the predatory behaviour of Podarcis sicula (Reptilia: Lacertidae) towards aposematic and non-aposematic preys. Amphibia-Reptilia, 29(3), 449-453.

Bonacci, T., Aloise, G., Brandmayr, P., Cagnin, M., \& Brandmayr, T. Z. (2004). Behavioural responses of Crocidura leucodon (Insectivora, Soricidae) to arthropod preys with various antipredator defenses. Hystrix, the Italian Journal of Mammalogy, 15(1).

Bonacci, T., Massolo, A., Brandmayr, P., \& Brandmayr, T. Z. (2006). Predatory behaviour on ground beetles (Coleoptera: Carabidae) by Ocypus olens (Müller) (Coleoptera: Staphylinidae) under laboratory conditions. Entomological News, 117(5) 545-551.

Bowdish, T. I., \& Bultman, T. L. (1993). Visual cues used by mantids in learning aversion to aposematically colored prey. American Midland Naturalist, 215-222.

Brandmayr, T. Z., Bonacci, T., Mazzei, A., \& Brandmayr, P. (2008) Defensive strategies against predators in Carabid beetles. Proceedings of the XIII European Carabidologists Meeting. 325-338.

Bybee, S. M., Johnson, K. K., Gering, E. J., Whiting, M. F., \& Crandall, K. A. (2012). All the better to see you with: a review of odonate color vision with 
transcriptomic insight into the odonate eye. Organisms Diversity \& Evolution, 12(3), 241-250.

Chiao, C. C., Wickiser, J. K., Allen, J. J., Genter, B., \& Hanlon, R. T. (2011). Hyperspectral imaging of cuttlefish camouflage indicates good color match in the eyes of fish predators. Proceedings of the National Academy of Sciences, 108(22), 9148-9153.

Church, S. C., Bennett, A. T. D., Cuthill, I. C. et al. (1998b). Does lepidopteran larval crypsis extend into the ultraviolet? - Naturwissenschaften 85: 189-192.

Corbet, P. S. (1999). Dragonflies: behaviour and ecology of Odonata. Harley Books.

Cott, H. B. (1940). Adaptive coloration in animals.

Cuthill, I. C., and Bennett, A. T. (1993). Mimicry and the eye of the beholder. Proceedings of the Royal Society of London. Series B: Biological Sciences 253: 203-204.

Dunham, M.J. (1992a). Determinants of territory-holding duration in Pachydiplax longipennis (Odonata: Libellulidae). BNABS 9:112 (abstract only).

Edmunds, M. (1974). Defence in animals: a survey of anti-predator defences. Longman Publishing Group.

Endler, J. A., \& Mappes, J. (2004). Predator mixes and the conspicuousness of aposematic signals. The American Naturalist, 163(4), 532-547. 
Exernova, A., Stys, P., Fucikova, E., Vesela, S., Svadova, K., Prokopova, M., Jarosik, V., Fuchs, R., Landova, E. (2007). Avoidance of aposematic prey in European tits (Paridae): learned or innate?. Behavioral Ecology, 18(1), 148-156.

Fabricant, S. A., \& Herberstein, M. E. (2014). Hidden in plain orange: aposematic coloration is cryptic to a colorblind insect predator. Behavioral Ecology, 26(1), $38-44$.

Fabricant, S. A., \& Smith, C. L. (2014). Is the hibiscus harlequin bug aposematic? The importance of testing multiple predators. Ecology and evolution, 4(2), 113-120.

Forsman, A., \& Merilaita, S. (1999). Fearful symmetry: pattern size and asymmetry affects aposematic signal efficacy. Evolutionary Ecology, 13(2), 131-140.

Gamberale, G., \& Tullberg, B. S. (1996). Evidence for a peak-shift in predator generalization among aposematic prey. Proceedings of the Royal Society of London B: Biological Sciences, 263(1375), 1329-1334.

Gamberale, G., \& Tullberg, B. S. (1998). Aposematism and gregariousness: the combined effect of group size and coloration on signal repellence. Proceedings of the Royal Society of London B: Biological Sciences, 265(1399), 889-894.

Gamberale-Stille, G., \& Tullberg, B. S. (2001). Fruit or aposematic insect? Contextdependent colour preferences in domestic chicks. Proceedings of the Royal Society of London B: Biological Sciences, 268(1485), 2525-2529.

Gelperin, A. (1968). Feeding behaviour of the praying mantis: a learned modification. Nature, 219, 399-400. 
Gittleman, J. L., \& Harvey, P. H. (1980). Why are distasteful prey not cryptic?. Nature.

Grundy, P. R., Maelzer, D. A., Bruce, A., \& Hassan, E. (2000). A mass-rearing method for the assassin bug Pristhesancus plagipennis (Hemiptera: Reduviidae). Biological Control, 18(3), 243-250.

Guilford, T. (1990). The evolution of aposematism. In: Insect Defenses: Adaptive Mechanisms and Strategies of Prey and Predators (Ed. By D. L. Evans \& J. O. Schmidt), pp. 23-61. Albany: State University of New York Press.

Guillermo-Ferreira, R., Bispo, P. C., Appel, E., Kovalev, A., \& Gorb, S. N. (2015). Mechanism of the wing colouration in the dragonfly Zenithoptera lanei (Odonata: Libellulidae) and its role in intraspecific communication. Journal of insect physiology, 81, 129-136.

Hagman, M., \& Forsman, A. (2003). Correlated evolution of conspicuous coloration and body size in poison frogs (Dendrobatidae). Evolution, 57(12), 2904-2910.

Halpin, C. G., Skelhorn, J., \& Rowe, C. (2013). Predators' decisions to eat defended prey depend on the size of undefended prey. Animal behaviour, 85(6), 1315-1321.

Hansen, B., Bjornsen, P. K., \& Hansen, P. J. (1994). The size ratio between planktonic predators and their prey. Limnology and oceanography, 39(2), 395-403.

Harland, D. P., Li, D., \& Jackson, R. R. (2012). How jumping spiders see the world. How animals see the world: comparative behavior, biology, and evolution of vision. | Oxford University Press, New York, 133-164. 
Hart, N. S., \& Hunt, D. M. (2007). Avian visual pigments: characteristics, spectral tuning, and evolution. The American Naturalist, 169(S1), S7-S26.

Hatle, J. D., \& Salazar, B. A. (2001). Aposematic coloration of gregarious insects can delay predation by an ambush predator. Environmental Entomology, 30(1), 51-54.

Hisada, M., Tamasige, M., \& Suzuki, N. (1965). Control of the flight of the dragonfly Sympetrum darwinianum. Journal of the Faculty of Science Hokkaido University. Series 6 Zoology, 15(4), 568-577

Hossie, T. J., \& Sherratt, T. N. (2012). Eyespots interact with body colour to protect caterpillar-like prey from avian predators. Animal Behaviour, 84(1), 167-173.

Iwasaki, T. (1990). Predatory behavior of the praying mantis, Tenodera aridifolia I. Effect of prey size on prey recognition. Journal of Ethology, 8(2), 75-79.

Jackson, R. R., \& Pollard, S. D. (1996). Predatory behavior of jumping spiders. Annual review of entomology, 41(1), 287-308.

Jones, C. D., Kingsley, A., Burke, P., \& Holder, M. (2008). Field Guide to the Dragonflies and Damselflies of Algonquin Provincial Park and the Surrounding Area. The Friends of Algonquin Park. Whitney, ON.

Jones, R. S., Fenton, A., \& Speed, M. P. (2016). "Parasite-induced aposematism” protects entomopathogenic nematode parasites against invertebrate enemies. Behavioral Ecology, 27(2), 645-651. 
Kauppinen, J., \& Mappes, J. (2003). Why are wasps so intimidating: field experiments on hunting dragonflies (Odonata: Aeshna grandis). Animal Behaviour, 66(3), 505511.

Kazemi, B., Gamberale-Stille, G., Tullberg, B. S., \& Leimar, O. (2014). Stimulus salience as an explanation for imperfect mimicry. Current Biology, 24(9), 965969.

Kelber A. (2006). Invertebrate colour vision. In: Warrant EJ, Nilsson DE, editors. Invertebrate vision. Cambridge (UK): Cambridge University Press. p. 250-290.

Koch, K. (2014). Hand feeding: a method to increase the survival rate of Orthetrum coerulescens (Odonata: Libellulidae) in outdoor enclosures. International Journal of Odonatology, 17(1), 1-6.

Land MF, Nilsson D. (2012). Animal eyes. Oxford: Oxford University Press.

Long, S. M., Lewis, S., Jean-Louis, L., Ramos, G., Richmond, J., \& Jakob, E. M. (2012). Firefly flashing and jumping spider predation. Animal Behaviour,83(1), 81-86.

Malcolm, S. B. (1986). Aposematism in a soft-bodied insect: a case for kin selection. Behavioral Ecology and Sociobiology, 387-393.

Mappes, J., Marples, N., \& Endler, J. A. (2005). The complex business of survival by aposematism. Trends in Ecology \& Evolution, 20(11), 598-603. 
Marden, J. (1995). Large-scale changes in thermal sensitivity of flight performance during adult maturation in a dragonfly. Journal of Experimental Biology, 198(10), 2095-2102.

Marples, N. M., \& Kelly, D. J. (1999). Neophobia and dietary conservatism: two distinct processes?. Evolutionary Ecology 13: 641-653.

Marples, N. M., Kelly, D. J., \& Thomas, R. J. (2005). Perspective: the evolution of warning coloration is not paradoxical. Evolution 59: 933-940.

Marples, N. M., Roper, T. J., \& Harper, D. G. (1998). Responses of wild birds to novel prey: evidence of dietary conservatism. Oikos, 161-165.

Marples, N. M., van Veelen, W., \& Brakefield, P. M. (1994). The relative importance of colour, taste and smell in the protection of an aposematic insect Coccinella septempunctata. Animal Behaviour, 48(4), 967-974.

McIver, J. D., \& Lattin, J. D. (1990). Evidence for aposematism in the plant bug Lopidea nigridea Uhler (Hemiptera: Miridae: Orthotylinae). Biological Journal of the Linnean Society, 40(2), 99-112.

Mischiati, M., Lin, H. T., Herold, P., Imler, E., Olberg, R., \& Leonardo, A. (2015). Internal models direct dragonfly interception steering. Nature, 517(7534), 333338.

Morris, R. L., \& Reader, T. (2016). Do crab spiders perceive Batesian mimicry in hoverflies?. Behavioral Ecology, arv233. 
Murphy, S. M., Leahy, S. M., Williams, L. S., \& Lill, J. T. (2010). Stinging spines protect slug caterpillars (Limacodidae) from multiple generalist predators. Behavioral Ecology, 21(1), 153-160.

Murray, E. M., Bolton, S. K., Berg, T., \& Saporito, R. A. (2016). Arthropod predation in a dendrobatid poison frog: does frog life stage matter?. Zoology, 119(3), 169-174.

Nelson, X. J., Jackson, R. R., Li, D., Barrion, A. T., \& Edwards, G. B. (2006). Innate aversion to ants (Hymenoptera: Formicidae) and ant mimics: experimental findings from mantises (Mantodea). Biological Journal of the Linnean Society, 88(1), 23-32.

Nentwig, W., \& Wissel, C. (1986). A comparison of prey lengths among spiders. Oecologia, 68(4), 595-600.

O'Donnell, S. (1996). Dragonflies (Gynacantha nervosa Rambur) avoid wasps (Polybia aequatorialis Zavattari and Mischocyttarus sp.) as prey. Journal of insect behavior, 9(1), 159-162.

Olberg, R. M., Worthington, A. H., \& Venator, K. R. (2000). Prey pursuit and interception in dragonflies. Journal of Comparative Physiology A, 186(2), 155162.

Olberg, R. M., Worthington, A. H., Fox, J. L., Bessette, C. E., \& Loosemore, M. P. (2005). Prey size selection and distance estimation in foraging adult dragonflies. Journal of Comparative Physiology A, 191(9), 791-797.

Pearson, D. L. (1985). The function of multiple anti-predator mechanisms in adult tiger beetles (Coleoptera: Cicindelidae). Ecological entomology, 10(1), 65-72. 
Penney, H. D., Hassall, C., Skevington, J. H., Abbott, K. R., \& Sherratt, T. N. (2012). A comparative analysis of the evolution of imperfect mimicry. Nature, 483(7390), 461-464.

Poulton, E. B. (1890). The colours of animals: their meaning and use, especially considered in the case of insects. D. Appleton.

Prudic, K. L., Skemp, A. K., \& Papaj, D. R. (2007). Aposematic coloration, luminance contrast, and the benefits of conspicuousness. Behavioral Ecology, 18(1), 41-46.

Rafter, J. L., Agrawal, A. A., \& Preisser, E. L. (2013). Chinese mantids gut toxic monarch caterpillars: avoidance of prey defence?. Ecological Entomology, 38(1), $76-82$.

Rashed, A., Beatty, C. D., Forbes, M. R., \& Sherratt, T. N. (2005). Prey selection by dragonflies in relation to prey size and wasp-like colours and patterns. Animal behaviour, 70(5), 1195-1202.

Reader, T., \& Hochuli, D. F. (2003). Understanding gregariousness in a larval Lepidopteran: the roles of host plant, predation, and microclimate. Ecological Entomology, 28(6), 729-737.

Reitze, M., \& Nentwig, W. (1991). Comparative investigations into the feeding ecology of six Mantodea species. Oecologia, 86(4), 568-574.

Roper, T. J., \& Marples, N. M. (1997). Odour and colour as cues for taste-avoidance learning in domestic chicks. Animal Behaviour, 53(6), 1241-1250. 
Rowe, C., \& Halpin, C. (2013). Why are warning displays multimodal?. Behavioral Ecology and Sociobiology, 67(9), 1425-1439.

Ruxton, G. D., Sherratt, T. N., \& Speed, M. P. (2004). Avoiding attack. Oxford University Press.

Shelly, T. E., \& Pearson, D. L. (1978). Size and color discrimination of the robber fly Efferia tricella (Diptera: Asilidae) as a predator on tiger beetles (Coleoptera: Cicindelidae). Environmental Entomology, 7(6), 790-793.

Sherratt, T. N. (2002). The coevolution of warning signals. Proceedings of the Royal Society of London B: Biological Sciences, 269(1492), 741-746.

Skelhorn, J., Halpin, C. G., \& Rowe, C. (2016). Learning about aposematic prey. Behavioral Ecology, arw009.

Skelhorn, J., Rowland, H. M., \& Ruxton, G. D. (2010). The evolution and ecology of masquerade. Biological Journal of the Linnean Society, 99(1), 1-8.

Skow, C. D., \& Jakob, E. M. (2006). Jumping spiders attend to context during learned | avoidance of aposematic prey. Behavioral Ecology, 17(1), 34-40.

Symondson, W. O. C., Sunderland, K. D., \& Greenstone, M. H. (2002). Can generalist predators be effective biocontrol agents? 1. Annual review of entomology, 47(1), $561-594$.

Tabadkani, S. M., \& Nozari, J. (2014). Relaxed predation hinders development of antipredator behaviors in an aposematic beetle. Entomologia Experimentalis et Applicata, 153(3), 199-206. 
Taylor, L. A., Amin, Z., Maier, E. B., Byrne, K. J., \& Morehouse, N. I. (2016). Flexible color learning in an invertebrate predator: Habronattus jumping spiders can learn to prefer or avoid red during foraging. Behavioral Ecology, 27(2), 520-529.

Taylor, L. A., Maier, E. B., Byrne, K. J., Amin, Z., \& Morehouse, N. I. (2014). Colour use by tiny predators: jumping spiders show colour biases during foraging. Animal Behaviour, 90, 149-157.

Thomas, R. J., King, T. A., Forshaw, H. E., Marples, N. M., Speed, M. P., \& Cable, J. (2010). The response of fish to novel prey: evidence that dietary conservatism is not restricted to birds. Behavioral Ecology, arq037.

Thomas, R. J., Marples, N. M., Cuthill, I. C., Takahashi, M., \& Gibson, E. A. (2003). Dietary conservatism may facilitate the initial evolution of aposematism. Oikos, 101(3), 458-466.

Tscharntke, T. (1992). Cascade Effects Among Four Trophic Levels: Bird Predation on Galls Affects Density-Dependent Parasitism. Ecology, 73(5), 1689-1698.

Wallace, A. R. (1889). Darwinism: An Exposition of the Theory of Natural Selection, with Some of the Applications. Macmillan.

Wiklund, C., \& Järvi, T. (1982). Survival of distasteful insects after being attacked by naive birds: a reappraisal of the theory of aposematic coloration evolving through individual selection. Evolution, 998-1002.

Yang, E. C., \& Osorio, D. (1996). Spectral responses and chromatic processing in the dragonfly lamina. Journal of Comparative Physiology A, 178(4), 543-550. 